\title{
Epigenetic Mechanisms of Genomic Imprinting: Common Themes in the Regulation of Imprinted Regions in Mammals, Plants, and Insects
}

\author{
William A. MacDonald1,2 \\ ${ }^{1}$ Department of Biology, Dalhousie University, Halifax, NS, Canada B3H 4R2 \\ ${ }^{2}$ Departments of Biochemistry and Obstetrics \& Gynecology, University of Western Ontario's Schulich School of Medicine and Dentistry, \\ Children's Health Research Institute, London, ON, Canada N6C 2V5
}

Correspondence should be addressed to William A. MacDonald, wmacdon7@uwo.ca

Received 16 July 2011; Accepted 26 September 2011

Academic Editor: Kathleen Fitzpatrick

Copyright (C) 2012 William A. MacDonald. This is an open access article distributed under the Creative Commons Attribution License, which permits unrestricted use, distribution, and reproduction in any medium, provided the original work is properly cited.

Genomic imprinting is a form of epigenetic inheritance whereby the regulation of a gene or chromosomal region is dependent on the sex of the transmitting parent. During gametogenesis, imprinted regions of DNA are differentially marked in accordance to the sex of the parent, resulting in parent-specific expression. While mice are the primary research model used to study genomic imprinting, imprinted regions have been described in a broad variety of organisms, including other mammals, plants, and insects. Each of these organisms employs multiple, interrelated, epigenetic mechanisms to maintain parent-specific expression. While imprinted genes and imprint control regions are often species and locus-specific, the same suites of epigenetic mechanisms are often used to achieve imprinted expression. This review examines some examples of the epigenetic mechanisms responsible for genomic imprinting in mammals, plants, and insects.

\section{Introduction}

Epigenetic regulation of the genome is a critical facet of development. Epigenetic control of gene expression allows heritable changes in gene expression without the need for alterations in DNA sequence. This is achieved through the recruitment of molecular processes that assist transcription, block transcription, or degrade existing transcripts. Genomic imprinting is an epigenetic process that marks DNA in a sexdependent manner, resulting in the differential expression of a gene depending on its parent of origin. Achieving an imprint requires establishing meiotically stable male and female imprints during gametogenesis and maintaining the imprinted state through DNA replication in the somatic cells of the embryo. Erasure of the preceding generation's imprint occurs in the germ line, followed by imprint reestablishment, in accordance with the sex of the organism. Each step in this imprinting process requires epigenetic marks to be interpreted by the genome and acted upon accordingly to result in parent-specific gene expression.
Genomic imprinting has been widely reported in eutherian mammals and marsupials [1-3]. Mice comprise the primary research model organism for the study of genomic imprinting. Approximately one hundred imprinted genes have been identified in mice with many more predicted to be present $[2,4]$. This review considers imprinting to include chromosomal domains that direct imprinted epigenetic regulation, even if endogenous transcriptional units have yet to be identified as imprinting targets. Many imprinted genes in mice are developmentally important, linked to the formation of the placenta, or involved in brain function $[2,5,6]$. Noncoding transcriptional units, such as noncoding RNA, can also be imprinted and often form imprinted domains with developmentally important imprinted genes [7]. Imprinted genes found in mice are often used as candidates for investigating imprinted genes in other mammals. While some imprinted genes are conserved in mammals, many imprinted genes do not retain their imprinted status, even across eutherian mammals $[1,2]$. For example, only a portion of the imprinted genes identified 
in mice are also known to be imprinted in humans [2], with placental-specific imprinted genes standing out in this discordance [8]. This demonstrates that imprinting cannot be predicted in nonmodel species simply by monitoring homologous genes. Additionally, this does not preclude the presence of imprinted genes or imprinted chromosomal regions being present in species outside of the existing documented examples. Determining how imprinting is lost in orthologous genes and what epigenetic changes are found within these regions can lead to a better understanding of how imprinted domains might be regulated.

In addition to mammals and marsupials, imprinted genes have also been identified in flowering plants [9, 10]. Imprinted chromosomes and chromosomal regions have been reported in insects [11], while transgenes have identified imprinted chromosomal regions in fish [12] and nematodes $[13,14]$. Imprinted domains in chromosomal regions with unidentified target genes are seemingly dissociated from significantly influencing the development of these organisms, however, they are still subject to parent-specific epigenetic modifications and provide insight into the overall organization and mechanisms of genomic imprinting. While the function and characteristics of imprinted loci vary, both between and within organisms, there are some common themes of genomic imprinting. Many imprinted regions are either arranged in restrictive chromosomal areas or regulated as multigene clusters, indicating imprinted regions are contained as distinct structural domains. This organization may be related to the close association of imprinted domains to regions of the chromosome containing tandem repeats or transposable elements $[9,11,15,16]$. It has further been suggested that these distinct imprinted domains could have a broader function to maintain genome integrity and assist in chromosome pairing, possibly contributing to the presence of such domains in diverse organisms [17].

In this review, the epigenetic mechanisms involved in the regulation of imprinted domains in mammals, Arabidopsis, and Drosophila are explored. Mice represent the archetypal model for genomic imprinting and will be used to illustrate the differing roles of epigenetic mechanisms involved in regulating distinct imprinted domains. Arabidopsis is an emerging model organism for the study of genomic imprinting, where imprinting is pronounced in the endosperm but not the embryo proper. Drosophila are a model organism with a rich history in epigenetic research that have been utilized for transgenic imprinting element experiments while also having characterized imprinted chromosomal regions, despite not having any identified endogenously imprinted genes. Much remains to be understood about epigenetic regulation of genomic imprints. As epigenetic research expands to diverse model and nonmodel organisms, comparisons can be made between the structure and mechanisms of imprinted domains.

\section{Common Epigenetic Mechanisms}

The imprinted domains of mammals, plants, and insects represent distinct imprint events that do not share conserved sequence origins. While there are no universal templates that can be applied adequately to explain the regulation of all imprinted domains, either within or between organisms, there are common themes in the epigenetic mechanisms utilized and the multiple levels of regulation required to execute this parent-dependent mode of inheritance. As an epigenetic process, genomic imprinting alters gene expression without altering DNA sequence. However, DNA sequences are important in demarcating an imprinted domain. Imprinting control regions (ICRs) are often composed of repetitive DNA sequences found flanking, or internal to, imprinted genes, and in most cases, removal of an ICR will result in a loss of imprinting. Epigenetic modifiers of gene expression such as DNA methylation, histone modification, non-RNA, and higher-order chromatin formation act within ICRs to establish and maintain the imprinted state. ICRs act as nucleation sites for gene silencing or activation and are able to regulate expression of a single gene or an entire gene cluster. Enhancers and boundary elements are often associated with ICRs to restrict imprinted regulation to specific domains.

\section{DNA Methylation}

DNA methylation, the first epigenetic mechanism to be associated with imprinting, is an epigenetic modification that is applied directly to a strand of DNA $[18,19]$. DNA methyltransferases (Dnmt) are highly conserved classes of enzymes that transfer methyl groups onto cytosine-C5 and are essential for both mammal and plant genome stability [20, 21], while being dispensable for the viability of Drosophila, which have low levels of genomic DNA methylation [22]. In plants and mammals, many ICRs contain differentially methylated regions (DMRs) that direct the epigenetic regulation of imprinted domains. Methylation within DMRs is often applied during gametogenesis and subsequently maintained throughout development, demonstrating the importance of DNA methylation for both the establishment and maintenance of many imprinted domains.

\section{Histone Modification}

Histone proteins and the modifications applied to them are highly conserved and comprise the most pervasive elements of imprinting across all taxa. Nuclear DNA is wrapped around nucleosomes, histone octamers composed of histones $\mathrm{H} 2 \mathrm{~A}, \mathrm{H} 2 \mathrm{~B}, \mathrm{H} 3$, and, $\mathrm{H} 4$, to form the basic repeating unit of chromatin. Various epigenetic modifications can be applied to the histones that affect chromatin conformation. Histone acetylation generally creates an accessible chromatin conformation while histone deacetylation, often coupled to histone methylation, initiates a compressed chromatin conformation that promotes silencing and the formation of heterochromatin [23]. Histone methylation can confer both an active or repressed transcriptional state depending upon which lysine is methylated. Histone 3 lysine 9 (H3K9), histone 4 lysine 20 (H4K20), and histone 3 lysine 27 (H3K27) are silencing modifications, while histone 3 lysine 4 (H3K4) 
methylation produces active chromatin [24]. Histone modifications and DNA methylation are often intertwined, each epigenetic mark can influence the other's recruitment to reinforce differential epigenetic states $[25,26]$. Histone modifications at imprinted regions can also facilitate the formation of higher-order chromatin structures.

\section{Higher-Order Chromatin Structures}

Maintaining transcriptional inactivation of an imprinted allele often involves the formation of heterochromatin, a compacted chromatin structure that can spread in cis and generally impose transcriptional silencing. Heterochromatic regions remain stable throughout development and are propagated through cell division by late replication in $S$ phase of the cell cycle [27]. Heterochromatic protein 1 (HP1) is a highly conserved nonhistone chromatin protein that is able to recruit other heterochromatic proteins and accessory factors, such as histone methyltransferases, to reinforce the structure of heterochromatin and initiate spreading in cis [28-30]. Polycomb group proteins form a silencing pathway largely parallel to heterochromatic silencing that targets homeotic genes [31]. Polycomb group silencing also involves histone deacetylases and histone methyltransferases, however, there is only modest overlap between Polycomb group and heterochromatic silencing.

\section{Noncoding RNA, Antisense RNA, and RNA Interference}

RNA interference (RNAi) is a highly conserved posttranscriptional silencing mechanism in which double-stranded RNA (dsRNA) are processed to form guides for the degredation of complementary RNA transcripts through an RNA silencing complex (RISC) [32, 33]. The production of noncoding RNA has been described at multiple imprinted regions in both mammals and plants [7, 34]. In many organisms, components of the RNAi silencing pathway are found to be involved in the recruitment DNA methyltransferases and other factors that facilitate higher-order chromatin structure [35]. As more imprinted domains in diverse organisms become characterized, noncoding RNA and RNAi may be found to have a significant role in the regulation of genomic imprinting.

\section{Imprinting in Mammals}

In mammals, most known imprinted genes are organized into clusters that share common ICRs to direct the parentspecific regulation of multiple genes within the cluster. Many mammalian ICRs contain differentially methylated regions (DMRs) that gain parent-specific DNA methylation marks either in the germline for imprint establishment, or in somatic cells for imprint maintenance. A survey of both human and mouse genomes found more tandem repeats in methylated regions of imprinted genes than methylated regions of nonimprinted genes [36]. The presence of these repeats may represent additional structural elements in imprinted regions that could direct chromatin alterations or recruit additional epigenetic mechanisms. The presence of noncoding RNA is another common feature of mammalian imprinting. In mice, extensive transcription of noncoding RNA has been reported at multiple imprinted loci, with many of these transcripts extending beyond the previously established boundaries of imprinted regions [37].

\section{DNA Methylation and Igf2-H19 Imprinting in Mammals}

The mouse insulin-like growth factor 2 (Igf2) and H19 genes were among the first imprinted genes to be characterized in detail $[38,39]$. Subsequently, the same imprinting pattern was found for the human Igf2 and H19 genes [40, 41], leading to the imprinted status of Igf2 becoming a standard assay for determining the presence of genomic imprinting in other vertebrates such as fish, birds, marsupials, sheep, and cattle [42-46]. The reciprocal imprinting of the Igf2 and $H 19$ genes is mechanistically coupled. H19 is maternally expressed and Igf2 paternally expressed (Figure 1(a)). Two ICRs exist for Igf2 and both are paternally methylated. DMR1, which is upstream of $\operatorname{Ig} f 2$ promoter 1 , is a silencer that is inactivated by methylation [47]. DMR2 is located in exon 6 of Igf2 and is an enhancer activated by methylation [48]. H19 has one ICR which is located upstream of the H19 gene and is also paternally methylated [49]. Regulation of the Igf2 and H19 imprinted domains is dependent on paternal-specific DNA methylation within the DMRs to maintain monoallelic expression; deletions of the H19 DMR and Igf2 DMR1 or alterations to Dnmts result in biallelic expression of both H19 and Igf2 [50]. Passage through the germline is required to establish Igf2/H19 DMR methylation [51], which is carried out by the Dnmt3a methyltransferase assisted by the Dnmt cofactor, Dnmt3L [52, 53]. Once established, paternal-specific methylation is then identified and maintained in somatic cells by Dnmt1 [54]. Dnmt1 cannot reestablish parent-specific DNA methylation patterns if prior methylation marks are lost [51].

During mouse preimplantation development, both paternal and maternal genomes undergo extensive demethylation a few hours after fertilization. The paternal genome is demethylated rapidly by active demethylation while the maternal genome passively looses DNA methylation during each cell cycle $[55,56]$. Imprinted DMRs must escape demethylation during preimplantation development to preserve any methylation marks established in the germline and this is achieved through the recruitment of maintenance methyltransferases to retain their methylated status [57]. In comparison to mice, sheep embryos have lower levels of genome reprogramming through preimplantation DNA demethylation [58], and only limited levels of active paternal genome demethylation [59]. An investigation into the epigenetic regulation of imprinted genes in sheep has found that parent-specific gene expression is not initiated until after the blastocyst stage, suggesting a later embryonic onset of parent-specific DNA methylation patterns [46]. Furthermore, $I g f 2$ and $H 19$ remain the only imprinted genes 


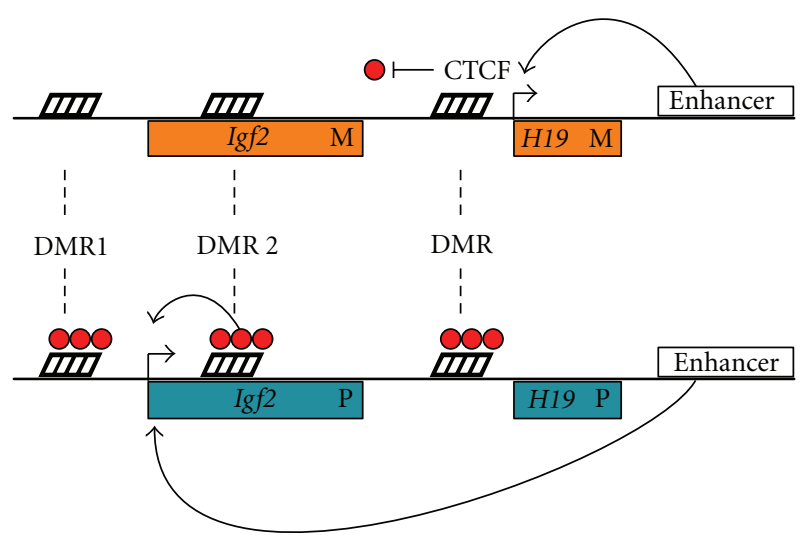

(a)

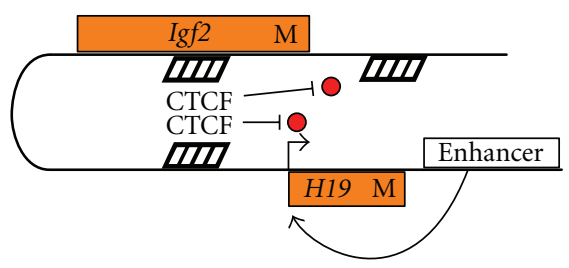

(b)

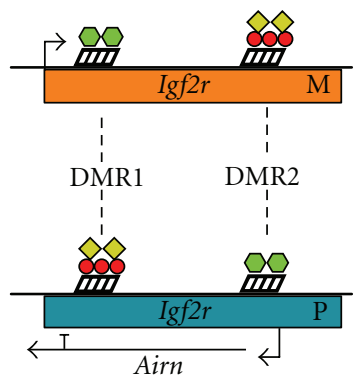

(c)

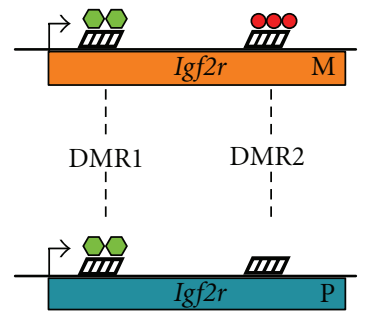

(d)

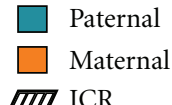

$\infty$ DNA methylation
$\diamond \mathrm{H} 3-\mathrm{K} 9$ methylation
$\infty \mathrm{H} 3-\mathrm{K} 4$ methylation

FIGURE 1: Imprinted regulation of Igf2/H19 and Igf2r/Airn in mice and humans. (a) The Igf2 and H19 genes are reciprocally imprinted, with H19 and Igf2 being expressed maternally and paternally, respectively. CTCF binds the maternal H19 ICR and acts as an insulator sequestering enhancers to initiate maternal $\mathrm{H} 19$ transcription while also protecting the H19 ICR from methylation. Methylation on the paternal H19 ICR prevents CTCF binding and silences paternal transcription. Igf2 is only expressed paternally as a lack of CTCF binding in the paternal H19 ICR allows enhancers to activate the Igf2 promoter. DMR1 is a silencer that is inactivated by methylation while DMR2 is an enhancer that is activated by methylation. DMR1 and DMR2 are both methylated on the paternal allele, facilitating paternal Igf2 transcription and blocking maternal transcription. (b) CTCF mediates an intrachromosomal loop, which prevents DNA methylation of the H19 DMR and Igf2 DMRs, while facilitating $H 19$ expression. (c) In mice, Igf2r is maternally expressed while the overlapping Airn antisense transcript is paternally expressed. Histone H3K4 methylation in the maternal Igf2r promoter (DMR1) initiates transcription, while DNA methylation and histone H3K9 methylation in the downstream Airn promoter region (DMR2) silences maternal Airn transcription. Activating H3K4 methylation at the paternal Airn promoter region initiates paternal transcription of the Airn transcript. The Airn transcript overlaps the Igf2 $r$ promoter and contributes to the silencing of the paternal Igf2r allele along with DNA methylation and histone H3K9 methylation. (d) In humans, Ifg $2 r$ is biallelically expressed. Activating H3K4 methylation is found in both the maternal and paternal promoter regions of Igf2r. While maternal-specific DNA methylation of DMR2 is maintained, there is no H3K4 methylation of paternal DMR2, preventing the transcription of the Airn transcript. 
in sheep that have identifiable germline DMR methylation, the DMRs of other investigated imprinted genes only acquire parent-specific methylation marks later in embryonic development $[46,60]$. Together, these results demonstrate that DNA methylation can be recruited to maintain silencing at imprinted regions that lack germline parent-specific DMRs, and that species-specific differences in genome regulation are reflected in the differential timing and recruitment of epigenetic mechanisms to maintain imprinted domains.

The Igf2 and H19 imprinted domains remain one of the most studied examples of imprinting but much remains to be elucidated about the involvement DNA methylation at this imprinted domain. Ectopic localization of the H19 DMR to a nonimprinted domain still results in paternalspecific DNA methylation of the DMR after fertilization despite the lack of germline establishment DNA methylation during spermatogenesis [61]. In order to achieve germline methylation of the ectopic H19 DMR, additional DNA elements downstream of the endogenous H19 DMR need to be included with the ectopic element [62]. These results suggest that more than DNA methylation alone is required to establish imprinting of this domain. Furthermore, in rare cases following DNA methylation disruption, a reversal of parent-specific imprinting patterns has been observed, including the H19 DMR gaining maternal DNA methylation and the paternal allele remaining unmethylated $[63,64]$. These rare events may be due to the disruption of intrachromosomal connections or nuclear localization of the parental alleles. The DMRs of Igf2 and H19 can physically interact, potentially initiating parent-specific chromosome loops separating the two domains into active or repressed nuclear compartments [65]. Such separation of maternal and paternal alleles into different nuclear compartments may provide additional reinforcement for the maintenance of parent-specific expression $[66,67]$.

\section{Chromatin Domains and the CTCF Insulator}

The evolutionarily conserved CCCTC-binding factor (CTCF) is also involved in Igf2 and H19 imprinting. Within the H19 ICR, there is a CCCTC binding site that is only functional on the maternal, unmethylated, allele. When CTCF binds the maternally unmethylated H19 ICR, it acts as an insulator, blocking access of the Igf2 promoter to enhancers [68]. Paternal methylation of the H19 ICR inhibits CTCF binding, allowing enhancers access to the Igf2 promoter on the paternal chromosome [69, 70]. Silencing of the Igf2 maternal allele is also facilitated by CTCF, which insulates maternal DMR1 and DMR2 from methylation when bound to the maternal H19 ICR [71]. A loss of CTCF function results in de novo methylation of the maternal H19 ICR, which effectively erases imprinted expression of H19 and Igf2 [72]. Recent phylogenetic and mutational analysis has shown that the CTCF binding sites, and not DNA methylation of ICRs, are the more reliable predictor of the imprinted expression of $I g f 2$. CTCF binding sites are conserved in humans, mice, and marsupials, which all have imprinted Igf2 and H19, while they are lacking in monotremes that do not imprint Igf2 or H19 [73]. Furthermore, Igf2 DMR2 is biallelically methylated in both marsupials and monotremes, even though it is only biallelically expressed in monotremes, showing that methylation alone does not cause imprinted expression [73].

CTCF binds numerous sites within mammalian genomes, where it is identified both as a transcriptional regulator and a chromatin insulator able to block the spread of heterochromatin and mediated long-range chromosomal interactions [74]. CTCF-directed intrachromosomal loops are thought to contribute to parent-specific expression of Igf2 and H19 (Figure 1(b)). Self-association between CTCF proteins bound to ICRs can initiate a chromosomal loop that isolates $H 19$ to maintain maternal expression, while reinforcing $\operatorname{Ig} f 2$ silencing through the creation of a repressive domain [75]. Disruption of CTCF binding to the maternal H19 ICR results in de novo DNA methylation of maternal Igf2 DMR1 and DMR2, suggesting that intrachromosomal looping mediates regulation of the entire maternal Igf2/H19 imprinted region [76]. Isolation of imprinted alleles by CTCF has been reported at various other mammalian imprinted domains, where parent-specific binding of CTCF is critical for maintaining active expression from an imprinted allele [77]. However, it remains to be determined if the initiation of higher-order chromatin structures via CTCF-mediated intrachromosomal looping is a common feature of other imprinted domains.

\section{Histone Modification and Mammalian Imprinting}

Although DNA methylation has been the focus of the majority of studies on genomic imprinting in mammals, it is becoming clear that histone modification and RNAbased processes also play a critical role. The receptor of Igf2, Igf2r, is another well-characterized imprinted gene [78]. Rodents and marsupials imprint their Igf2r gene, while monotremes, birds, and primates (including humans) do not, and thus they have biallelic Igf2r expression [79]. In mice, $I g f 2 r$ is maternally expressed, displaying a reciprocal pattern of imprinting to that of $\operatorname{Igf2}$ (Figure 1(c)). Two ICRs are present in Igf2r; the first, DMR1, is located in the Igf $2 r$ promoter region and is paternally methylated, and the second, DMR2, lies within the second intron of $\operatorname{Igf2} r$ and is maternally methylated. DMR2 corresponds to the promoter of an antisense RNA transcript Airn (formally Air), a large transcript that overlaps the promoter region of $\operatorname{Ig} f 2 r$ [80]. The Airn transcript is exclusively paternally expressed and not only contributes to the silencing of paternal $\operatorname{Ig} f 2 r$, but also to the silencing of the genes which are in the same region as Igf2 $r$ yet do not overlap the Airn transcript [80].

Histone methylation patterns are critical components of the parent-specific expression of $I g f 2 r$ and Airn genes. In mice, the expressed maternal $I g f 2 r$ allele and paternal Airn allele are both marked by $\mathrm{H} 3 \mathrm{~K} 4$ di- and trimethylation marks, while the repressed paternal Igf2 $r$ allele and maternal Airn allele are both marked by $\mathrm{H} 3 \mathrm{~K} 9$ trimethylation within the promoter region [81]. Indeed, histone methylation marks 
are more reflective of the imprinted state of $I g f 2 r$ than the presence of Airn transcripts or DNA methylation patterns. In the mouse brain, Igf $2 r$ is biallelically expressed. This correlates with the presence of activating H3K4 methylation in both the paternal and maternal Igf2 $r$ DMR1 promoter region, despite the retention of paternal Airn transcription [81]. In humans, activating $\mathrm{H} 3 \mathrm{~K} 4$ methylation is present within both the maternal and paternal Igf2 $r$ promoter regions (Figure $1(\mathrm{~d})$ ) yet is absent from the Airn promoter region, eliminating Airn expression while facilitating biallelic Igf2 $r$ expression [81]. Recently, H3K4 demethylation is shown as a requirement for establishing imprinted silencing at some maternally repressed genes in mice, where the disruption of $\mathrm{H} 3 \mathrm{~K} 4$ demethylation prevented de novo DNA methylation of DMRs [82]. H3K4 demethylation appeared critical for imprinted genes that undergo de novo DNA methylation at later stages in embryonic development, suggesting the interaction between histone modifications and DNA methylation may be dependent on the developmental timing of epigenetic regulatory activity.

A comprehensive survey of the histone modification present at imprinted regions compared to nonimprinted regions in mice determined three modifications closely associate with imprinted genes; repressed alleles contained $\mathrm{H} 3 \mathrm{~K} 9$ trimethylation and $\mathrm{H} 4 \mathrm{~K} 20$ trimethylation, while active alleles contained $\mathrm{H} 3 \mathrm{~K} 4$ trimethylation [83]. The chromatin state of imprinted regions was found to closely resemble heterochromatin and may be distinct from the general developmental silencing of genes, as H3K27 trimethylation was not present at all imprinted genes. The enrichment of $\mathrm{H} 3 \mathrm{~K} 4, \mathrm{H} 3 \mathrm{~K} 9$, and $\mathrm{H} 4 \mathrm{~K} 20$ trimethylation was present in imprinted genes regardless of whether the gene contained a DMR within its IRC, demonstrating both the importance and consistency of histone modification at imprinted domains. Broad enrichment of H3K27 trimethylation has been reported across some imprinted gene clusters [84]. This enrichment is occasionally biallelic and can be associated with both imprinted and nonimprinted genes alike within the same cluster [84]. Additionally, H3K27 trimethylation can also be disassociated from DNA methylation, or even antagonistic to DNA methylation within imprinted DMRs [85]. The complex association of H3K27 trimethylation with specific imprinted domains may be due to the secondary recruitment of $\mathrm{H} 3 \mathrm{~K} 27$ during development and tissue differentiation.

\section{Antisense Transcripts and Mammalian Imprinting}

The presence of noncoding RNA transcripts, such as the H19 and Airn RNAs, is associated with imprinted regions in mammals. Deletion of the DMR2 Airn promoter [86], or the truncation of the Airn transcript [80], results in paternal activation and biallelic expression of $\operatorname{Igf} 2 r$ and the neighboring gene clusters. Additionally, the Airn transcript is capable of maintaining paternal silencing in this gene cluster even if the paternal Igf2r promoter is experimentally activated [87] or if DNA methylation of DMR2 is lost [78]. Part of the silencing function of Airn may be the ability to recruit additional silencing complexes to the imprinted region. In the mouse placenta Airn can recruit the histone $\mathrm{H} 3 \mathrm{~K} 9$ methyltransferase G9a, which contributes to the imprinted silencing of the gene Slc22a3 within the Igf $2 r$ imprinted cluster [88]. Another important aspect of regulation by noncoding RNAs is the act of transcription itself and the interference such transcription can cause. It has been proposed that transcription of Airn through neighboring genes in cis contributes to their silencing [89]. Furthermore, the Airn transcript overlaps its own promoter and active transcription of Airn is required to prevent de novo methylation of this promoter on the paternal allele [90]. Recently, the transcriptional importance of noncoding RNAs been shown for the Kcnq1 imprinted domain. In stem cells, targeted depletion of the Kcnq1ot1 noncoding RNA did not relieve silencing of the paternally silenced genes, suggesting transcription through these genes during the production of Kcnq1ot1 contributes to their silencing more so than the presence of the Kcnq1ot1 transcript [91].

MicroRNAs (miRNAs) are endogenous 21-25 nt RNA transcripts that target complementary sequences for silencing [92]. Two miRNA genes, $m i R-127$ and $m i R-136$, have been shown to be part of an imprinted domain responsible for the imprinted expression of the retrotransposonlike gene Rtl1 in mice and the orthologous PEG11 gene in sheep and humans $[93,94]$. Imprinted expression is associated with an unmethylated maternal ICR, leading to the miRNA genes only being maternally expressed which drives maternal-specific silencing of Rtl1 [95]. In sheep, PEG11 produces a functional protein as well as an antisense PEG11 transcript [96]. Imprinted silencing is directed by maternally produced antisense miRNA acting as guides for RISC-mediated destruction of maternal PEG11 transcript [97]. However, complex modulations of maternal miRNA generation suggest that maternal gene expression levels are balanced for dosage and not completely silenced [96, 97]. It is unclear if RNAi processing of PEG11 transcripts by RNAi machinery recruits additional chromatic remodelers to regulate expression from the maternal allele.

Genomic imprinting has been linked to dosage compensation in some mammals, where the silencing is directed towards the paternal X chromosome [98]. In female mice, the paternal X chromosome is selectively silenced in extraembryonic tissues, in part by the production of the noncoding RNA Xist. Transcription of Xist spreads from an initial transcription site to cover most of the paternal X chromosome, leading to the recruitment of additional epigenetic silencing factors, such as histone methyltransferases and heterochromatic proteins [99]. Preferential silencing of the paternal X chromosome still occurs if Xist noncoding RNA is lost, however, silencing is destabilized [100]. This may be related to the finding that the RNAi component Dicer is required for the spread of Xist and recruitment of the $\mathrm{H} 3 \mathrm{~K} 27$ trimethylation silencing in somatic cell $\mathrm{X}$ inactivation [101]. It is possible that imprinted silencing of the paternal $\mathrm{X}$ chromosome in extraembryonic mouse tissues originates from the imprinted silencing of specific target genes or regions, which then act as nucleation sites for RNAi-directed spreading of silencing across the whole chromosome. 


\section{Imprinting in Plants}

Imprinting in plants was first documented in 1970, when it was found that a gene in maize produced fully colored kernels when maternally inherited and variegated kernels when paternally inherited [102]. In more recent years, genomic imprinting in angiosperms has been investigated extensively in Arabidopsis. Angiosperms experience double fertilization, with one sperm fusing the egg cell to produce the embryo proper, and the other fusing with the central cell to produce endosperm. The endosperm acts largely as support structure of the developing embryo and is terminally differentiated.

\section{DNA Methylation in Arabidopsis FWA and FIS2 Imprinting}

The Arabidopsis gene FWA encodes a homeodomaincontaining transcription factor involved in the regulation of flowering and is a well-characterized imprinted gene expressed solely from the maternal allele [103]. FWA imprinting involves DEMETER (DME), a DNA glycosylase able to excise modified nucleotide bases and the MET1 methyltransferase (Figure 2(a)). MET1 methylates tandem repeats in the FWA promoter and DME acts to remove methylated cytosines from the maternal FWA allele, leaving only the paternal FWA allele methylated $[103,104]$. If DME demethylation is lost, the imprint is also lost, as both maternal and paternal FWA alleles remain methylated by MET1 [103, 104]. This scenario implies methylation is the default state and active demethylation is required to imprint an allele. DME is primarily expressed in the female central cell before fertilization and is not expressed until long after fertilization or in the male sporophyte [105]. This disparity in DME expression provides a window during which the imprint can be established on the maternal FWA allele prior to fertilization but requires additional mechanisms to maintain expression after fertilization. FWA, FERTILIZATION INDEPENDENT SEED 2 (FIS2) is also maternally expressed and is regulated through the antagonistic action of DME and MET1 (Figure 2(b)). A distinct $200 \mathrm{bp}$ region upstream from FIS2 acts as the nucleation center for FIS2 paternal methylation but, unlike the MET1 methylation site in the FWA gene, there are no tandem repeats in this region [106]. For both FWA and FIS2, active MET1 methylation is required during male gametogenesis to produce paternalspecific silencing [106].

\section{RNAi and Heterochromatin Formation in Arabidopsis FWA Imprinting}

RNA-directed DNA methylation (RdDM) is a process that produces locus-specific heterochromatin formation in angiosperms and is attributed to the need to silence transposons. Initially, dsRNA is processed by RNAi machinery into small interfering RNAs (siRNA). These siRNA then guide site-specific DNA methylation and heterochromatinization [107]. Methylation produced by RdDM does not spread significantly in cis so silencing is precisely targeted to the region producing the dsRNA [108]. Heterochromatin formation arising from the RdDM pathway involves the ATPase chromatin-remodeling factor DECREASE IN DNA METHYLATION1 (DDM1), an SWI/SNF homologue involved with the maintenance of $\mathrm{H} 3 \mathrm{~K} 9$ histone methylation and DNA methylation [107].

The FWA promoter contains tandem repeats that produce dsRNA from the paternal FWA allele, which guides DDM1 methylation and heterochromatin formation [107]. The function of DDM1 is exclusively in the maintenance of silencing as FWA methylation cannot be reestablished by DDM1 after siRNA or DNA methylation is lost [109]. Mutations in genes involved in the RNAi pathway of Arabidopsis, including dicer-like 3 and argonaute4, result in a loss of paternal FWA methylation It has been proposed that the siRNA generated from the FWA promoter tandem repeats also guides DOMAINS REARRANGED METHYLTRANSFERASE (DRM), a Dmnt3 homologue, to perform de novo methylation [110]. This shows that the RNAi pathway in Arabidopsis can initiate silencing of targeted imprinted domains.

\section{Histone and Polycomb Group Proteins in Arabidopsis Imprinting}

The Arabidopsis Polycomb group protein MEDEA (MEA) gene is imprinted, resulting in expression exclusively from the maternal allele in the endosperm (Figure 2(c)). Similar to FWA and FIS2 imprinting, MEA regulation also involves DME activation and MET1 DNA methylation [111]. However, while DNA methylation is found in the promoter region of the paternal MEA allele, it likely does not play a large role in the initial regulation of the imprint [112]. Transcriptional activation of maternal MEA is maintained in the female central cell by DME [105], while the paternal MEA allele is silenced by H3K27 histone methylation [106]. Paternal MEA silencing is maintained by a Polycomb group complex, which includes FERTILIZATION INDEPENDENT ENDOSPERM (FIE), FIS2 and the maternally produced MEA [106, 113]. This Polycomb group complex is able to initiate a self-reinforcing loop of silencing, maintaining H3K27 methylation and recruiting additional Polycomb complexes.

MEA not only assists in regulating its own imprinted expression but also causes a cascade of imprinted expression in the genes that it regulates. The gene PHERES1 (PHE1) is regulated by the imprinted MEA protein and, as a consequence, is also imprinted [114]. PHE1 encodes a type I MADS-box protein, a protein family typically involved in DNA binding, and leads to uncontrolled endosperm proliferation when overexpressed. MEA, acting as part of a multiprotein complex with other Polycomb group proteins, forms condensed chromatin structures at its binding site within the PHE1 promoter which silences the PHE1 gene (Figure 2(d)) [115]. As only the maternal MEA allele is active prior to fertilization in the endosperm, PHE1 Polycomb silencing is also limited to the maternal allele [114]. The imprinting of both MEA and PHE1 demonstrates that the 
Male spermatophore
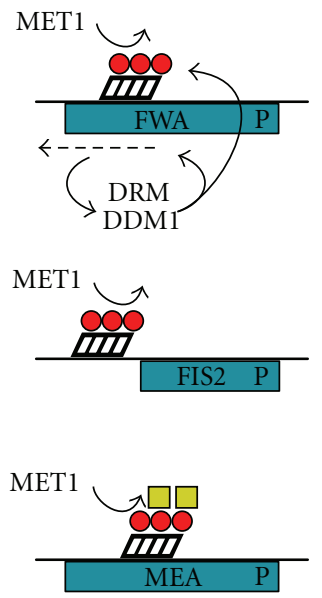

(b)

(a)
Female central cell
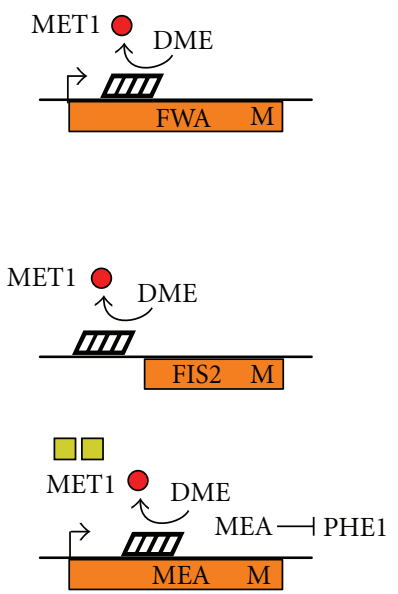

(c)

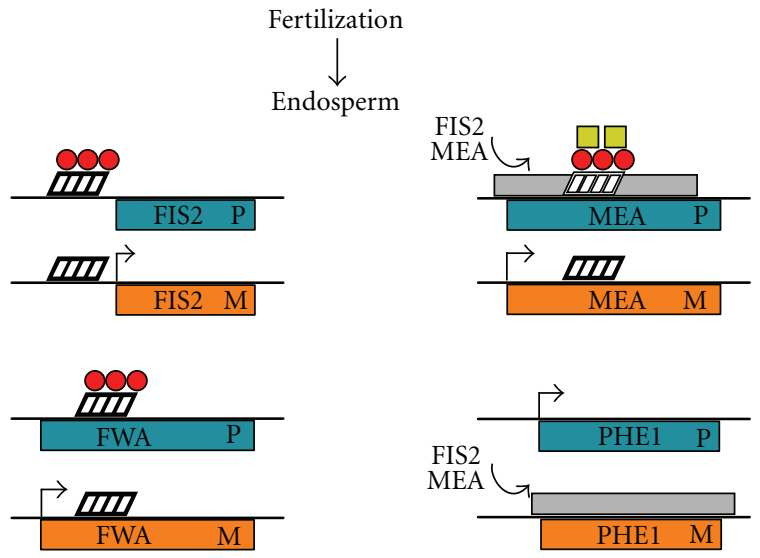

(d)

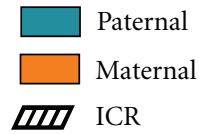

Polycomb group complex

○० DNA methylation

$\square \square$ H3-K27 methylation

FIGURE 2: Imprinted regulation of the Arabidopsis genes FWA, FIS2, MEA, and PHE1. (a) Imprinted FWA is only expressed from the maternal allele. Prior to fertilization, MET1 methylates the paternal FWA promoter. In the male spermatophores, tandem repeats in the promoter produce siRNA (represented by the dashed arrow), which recruit DRM and DDM1 to the promoter region to maintain the methylated state. In the female central cell, DME demethylates the maternal FWA promoter maintaining maternal expression. (b) The antagonistic relationship between MET1 and DME is also involved in the imprinting of FIS2. MET1 methylates a region upstream of the paternal FIS2 allele that initiates silencing while DME demethylates the maternal allele. (c) The imprinted regulation of MEA also involves MET1 and DME; however, histone modification plays a key role in initiating parent-specific expression. Histone H3K27 methylation is present in the promoter region of the paternal MEA allele in addition to DNA methylation. DME protects the maternal promoter from both DNA and histone methylation. Transcribed maternal MEA, which encodes a member of the Polycomb group silencing complex, initiates the parentspecific silencing of maternal PHE1. (d) In the endosperm, the Polycomb group gene MEA contributes to its own imprinted expression in the endosperm, with maternally produced MEA involved in the silencing of the paternal MEA allele. FIS2, which is also part of a Polycomb silencing complex, contributes to silencing the paternal MEA allele. PHE1, which is regulated by Polycomb group silencing, is only expressed from the paternal allele. Maternally produced FIS2 and MEA combine to maintain the silencing of the maternal PHE1 allele.

imprinting of a regulatory gene can produce a cascade of parent-specific gene expression. Recently, the gene Phf17 (Jade1), which encodes for a component of the HBO1 histone 4 acetylation complex, has been found to be imprinted in the mouse placenta [116]. This finding is interesting as it suggests the possibility of similar downstream imprinting events in the mouse placenta as those found in Arabidopsis endosperm.

\section{The mee1 Gene Is Imprinted in the Maize Embryo}

While all imprinted genes in Arabidopsis have so far been found to be monoallelically expressed only in the endosperm, a gene in maize, maternally expressed in embryo 1 (mee1), is reported to have parent-specific expression in both the 
endosperm and embryo [117]. Maternal-specific expression of mee1 in the endosperm is regulated in a manner similar to that described for Arabidopsis, with maternalspecific active DNA demethylation and protection from DNA methyltransferases. The paternal meel allele is methylated in gametes and remains methylated at all stages of development, preventing paternal transcription. The maternal allele is also methylated DNA in gametes; however, active demethylation of a DMR located near the transcriptional start site of mee 1 occurs after fertilization, suggesting that the initial parentspecific demarcation of the alleles is independent of DNA methylation. During gamete production, the maternal allele regains DNA methylation within the DMR. It remains to be determined which epigenetic mark establishes the maternal imprint but, it appears as though the meel DMR is in fact a differentially demethylated region, which may be a reflection of species-specific epigenetic reprogramming dynamics. Regardless, this finding illustrates the ability of the maize genome to maintain parent-specific demarcation of genes in the developing embryo, and predicts the identification of further genes with imprinted embryonic expression in plants.

\section{Imprinting in Insects}

The investigation of imprinting in insects has progressed quietly since early studies in Sciara and Coccids revealed that gene silencing induced by whole chromosome heterochromatinization was dependent on the parental origin of the chromosome $[118,119]$. It was the study of chromosome elimination in the fungus gnat, Sciara, which leads to the use of the descriptive term "imprint" [120]. Crouse reported that X chromosomes acquire an "imprint" which directs paternally derived $\mathrm{X}$ chromosomes to be eliminated from somatic cells and ensures that only the female X chromosomes remain in the gametes [120]. This work provided explicit evidence of parent-specific silencing. Whole chromosome imprinted regulation such as this is not uncommon in insects [121]; however, parent-specific transcriptional silencing of smaller chromosome regions, similar to that found in mammals and plants, has also been described in Drosophila.

\section{Genomic Imprinting in Drosophila}

Thus far, all imprinted domains in Drosophila melanogaster have been found only in chromosome regions that are heterochromatic [11]. In Drosophila, most heterochromatin is compartmentalized into large blocks such as those flanking the centromeres, the entire Y chromosome, and in a few discrete regions that are developmentally controlled. The relegation of imprinted domains to gene poor chromosomal regions is advantageous as it limits parentspecific silencing to relatively few genes [122]. This property also has made identifying endogenous imprinted genes in Drosophila difficult as these regions are mostly uncharacterized. Most known imprinted domains in Drosophila have been detected through position-effect variegation (PEV), which causes variegated transcriptional silencing of gene clusters placed adjacent to heterochromatic regions. Using transgenes or reporter genes placed into heterochromatic regions, imprinted domains have been identified by the display of parent-specific PEV silencing of the marker gene. The majority of the Drosophila Y chromosome is imprinted, as inserted transgenes are silenced in a parentspecific manner [123, 124], while distinct imprinted domains have been reported in heterochromatic regions of the $\mathrm{X}$ chromosome and the autosomes $[11,125,126]$.

\section{Imprinting of the Drosophila $D p(1 ; f) L J 9$ Mini-X Chromosome}

The Drosophila Dp(1:f)LJ9 mini-X chromosome is the result of an X chromosome inversion and deletion which juxtaposes euchromatic genes to a heterochromatic Drosophila imprinting center $[126,127]$. One of the euchromatic genes that falls under control from the imprinting center is the eye color gene garnet. This gene is uniformly expressed when maternally inherited and exhibits variegated silencing when paternally inherited, and so acts as a reporter for the imprint. Mutations which alter PEV by either enhanced silencing (E(var)) or suppressed silencing $(S u(v a r))$ do so by affecting proteins and accessory factors involved in heterochromatin formation. An extensive screen of the effects of $S u(v a r)$ mutations on imprinted garnet expression revealed that both HP1 (Su(var)2-5) and the H3K9 histone methyltransferase $(\mathrm{Su}$ (var)3-9) were required for the maintenance of the paternal imprint (Figure 3(a)) [128]. Additionally, a mutation of $\mathrm{Su}(v a r) 3-3$, responsible for H3K4 demethylation [129], also disrupted the silencing of the paternally inherited $D p(1: f) L J 9$ [128]. This suggests active removal of the activating H3K4 methylation mark is required before $\mathrm{H} 3 \mathrm{~K} 9$ methylation can direct HP1 recruitment and the formation of heterochromatin. While Polycomb group proteins have been implicated in the regulation of both mammalian and plant imprinting $[6,130]$, they do not appear to have any role in epigenetic regulation from the $D p(1: f) L J 9$ imprinting center. Mutations in Polycomb group genes, including Enhancer of zeste $E(z)$ which initiates $\mathrm{H} 3 \mathrm{~K} 27$ methylation, have no effect on paternal-specific silencing [128].

None of the $S u(v a r)$ mutations tested on $D p(1: f) L J 9$ had any effect on the stability of the maternal imprint, demonstrating that maternal inheritance of $D p(1: f) L J 9$ allows a stable boundary to form between the marker gene and the ICR to counteract heterochromatinization. The compact Drosophila genome utilizes many insulator proteins to create regulatory domains, but only the CTCF insulator protein is highly conserved $[131,132]$. Similar to the role of CTCF in maintaining mammalian imprinted domains, CTCF also acts to protect maternally inherited $D p(1: f) L J 9$ by acting as a boundary element against the spread of heterochromatin (Figure 3(b)) [133]. Other insulator proteins remain to be fully tested for their involvement in the $D p(1: f) L J 9$ maternalspecific boundary, however, Suppressor of Hairy-wing $(\mathrm{Su}(\mathrm{Hw}))$ and the Drosophila-specific Boundary Elementassociated Factor (BEAF-32) do not appear to be necessary 


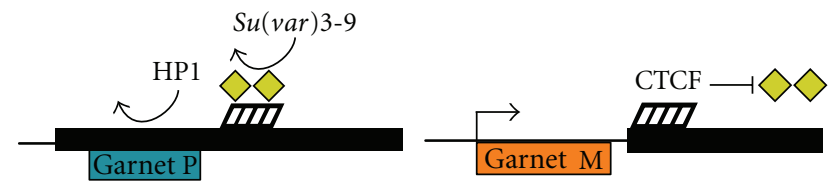

(a)

(b)
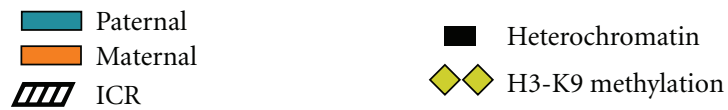

FIgURE 3: Creation of the Drosophila mini-X chromosome and the resulting imprinted expression of the garnet marker gene. The $D p(1: f) L J 9$ mini-X chromosome was generated through an inversion followed by a large deletion by X-ray irradiation. In the resulting mini-X chromosome, garnet is placed next to a region centric of heterochromatin containing an imprinting center. (a) Paternal transmission of the mini-X chromosome results in silencing of garnet, as a result of H3K9 methylation and heterochromatin formation. (b) Maternal transmission of the mini-X chromosome results in active transcription of the garnet gene, maintained by CTCF counteracting heterochromatin formation.

[134]. In Drosophila, many non-CTCF insulator proteins depend on PcG and Trx group proteins for proper function [135]. The failure of PcG and $\operatorname{Trx}$ group mutations to modify maternal Dp(1:f)LJ9 garnet expression [128] suggests non-CTCF insulators are not likely to be recruited to the maternal boundary. The specific involvement of CTCF with the $D p(1: f) L J 9$ imprint is intriguing as it raises the possibility that the imprint was acquired prior to Drosophila speciation or that the factors contributing imprint maintenance are more likely to involve conserved epigenetic mechanisms.

The role of heterochromatin at the $D p(1: f) L J 9$ imprint center is limited to imprint maintenance; no Su(var) mutations, Polycomb group protein mutations, or chemical heterochromatin modifiers impacted either the maternal or paternal establishment of the imprint [126, 128]. Similarly, CTCF is not involved in establishment of the maternal imprint [133], mirroring of its role in mammalian imprinting where it is also dispensable for imprint establishment [68, 136]. These findings illustrate the fact that distinct epigenetic mechanisms are used for the establishment and maintenance of parent-specific expression from the $D p(1: f) L J 9$ ICR. Establishment of the imprint requires correct passage through the germline, as evidenced by the loss of the Dp (1;f)LJ9 paternal imprint in cloned Drosophila [137].

Regulation of the $D p(1 ; f) L J 9$ imprinting center demonstrates features of both discrete mammalian ICRs and whole chromosome imprinting characteristics found in other insects. Paternal inheritance of the disrupted imprinting region results in the spreading of heterochromatic silencing to proximal areas; a similar spreading of silencing from an imprinted region has also been described in mammals [138]. However, a secondary effect of the exposed paternal $D p(1 ; f) L J 9$ ICR is a chromosome-wide decrease in transcription, similar to the imprinted silencing of whole chromosomes in Coccids [122]. The stable maternal boundary generated from the $D p(1 ; f) L J 9$ ICR prevents both the local spreading of heterochromatin and the chromosome-wide reduction of transcription [122]. This finding suggests that silencing initiated from a heterochromatic imprinted domain is able to impose long-range cis alterations in regulation when not properly insulated within a heterochromatic region.

\section{Noncoding RNA and Imprinting in Drosophila}

Drosophila dosage compensation involves an increase in male $\mathrm{X}$ chromosome expression instead of the silencing of one female $X$ chromosome, as occurs in mammals [139]. Increased transcription of the male $\mathrm{X}$ chromosome coincides with the binding of the male-specific lethal (MSL) complex, which is recruited to specific chromosome sites by the noncoding RNAs roX1 and roX2 [139]. Deletion of both roX genes eliminates compensated expression from genes on the X chromosome, resulting in male lethality [140]. Similar to the stabilization role of Xist in spreading of $\mathrm{X}$ chromosome silencing in mice, the MSL complex is still able to colocalize to specific $\mathrm{X}$ chromosome sites and direct limited activation in the absence of roX [139]. The spreading of MSL transcriptional activation, however, is dependent on roX RNA transcription [141]. Recently, it has been reported that experimental manipulation causing maternal inheritance of the $\mathrm{Y}$ chromosome significantly relieves male lethality caused by roX mutations, suggesting imprinted regions on the $\mathrm{Y}$ chromosome augment roX expression [142]. This suggests that correct passage of the $\mathrm{Y}$ chromosome through the male germline results in the establishment of epigenetic marks that influence dosage compensation in Drosophila. It has been proposed that the imprinted regions of the $\mathrm{Y}$ chromosome may contribute to hybrid incompatibility between Drosophila species [142], a phenomenon previously associated with imprinted genes in both mammals and plants $[143,144]$.

\section{DNA Methylation and Imprinting in Insects}

There is a precedent for the involvement of DNA methylation in insect imprinting in the mealybug Planococcus citri. Complete silencing of paternally inherited chromosomes in males is associated with DNA hypomethylation [145]. In this case, hypomethylated chromosomes, which have been inherited paternally, become silenced in males, while chromosomes inherited maternally remain hypermethylated and active. The epigenetic imprint marking paternal chromosomes for silencing appears to be $\mathrm{H} 3 \mathrm{~K} 9 \mathrm{di}$ - and trimethylation, 
which is established during gametogenesis, while the lack of $\mathrm{H} 3 \mathrm{~K} 9$ di- and trimethylation on the maternal chromosomes may simply reflect a default imprinted state [146]. Heterochromatic spreading reinforces the silent state of paternal chromosomes, as HP1-like and HP2-like complexes are recruited to chromosomes with $\mathrm{H} 3 \mathrm{~K} 9$ di- and trimethylated histones [147]. It is proposed that silencing of entire paternal chromosomes is nucleated from discrete ICRs marked by H3K9 di- and trimethylation, which escape early embryonic activation signals, and propagates chromosomal silencing [146]. Such spreading of silencing, originating from discrete ICRs to cover the entire chromosome, corresponds to the mechanisms guiding parent-specific chromosomal regulation described in Drosophila and mouse extraembryonic tissues.

Drosophila possess a single DNA methyltransferases, Dnmt2, and only have low genome-wide levels of DNA methylation that peak early in embryogenesis and decline towards adulthood $[22,148]$. The presence of DNA methylation in the developing embryo is defined developmentally, as nuclear concentrations peak in the early embryo then begin to decline as development progresses $[22,149]$. Drosophila with Dnmt2 mutations remain fertile and viable with no observable phenotype [22], however, overall lifespan is diminished [150]. Recently, Dnmt2 has been implicated in the genomic regulation of retrotransposons, suppressing retrotransposon transcription in somatic cells of the early embryo [151]. Loss of Dnmt2 resulted in the mislocalization of the H4K20 methyltransferase, resulting in the elimination of H4K20 trimethylation and reduced retrotransposon repression. Dnmt2 was also shown to be associated with heterochromatin formation at repeat transgene arrays, illustrating the potential for DNA methylation to assist in the recruitment and stabilization of heterochromatic factors in Drosophila [151].

The role of Dnmt2 in retrotransposon repression does not extend to the germline [151]. This finding is supported by research involving transgenic Drosophila with mammalian Dnmts; flies overexpressing mammalian Dnmts are not viable [152], however, germline-specific expression of mammalian Dnmts does not effect fertility or the viability of progeny [153]. Together, these findings suggest that genomic regulation by DNA methylation in Drosophila is restricted to somatic cells, and unlike mammals and plants, does not have an essential role in in the germline. While the role of DNA methylation in Drosophila development is still an area of great debate [154, 155], current research would suggest that DNA methylation is not a candidate for a germline establishment epigenetic mark in Drosophila imprinting.

\section{Recognition of Mammalian Imprinting Elements in Transgenic Drosophila}

Various transgenic Drosophila lines have been produced that contain either mouse or human ICRs [156-158]. These ICRs function as silencers in Drosophila but do not confer parentspecific silencing. Similar experiments involving human ICRs introduced into transgenic mice also resulted in a loss of parent-specific regulation $[159,160]$. Transgenic studies involving the mouse H19 ICR exemplify remarkable conservation of epigenetic function between the mouse and Drosophila genomes. A specific region of the upstream H19 ICR was identified as a silencing element in mice by first being identified as a required sequence for silencing in transgenic Drosophila [161]. Furthermore, the production of noncoding RNA transcripts from the upstream H19 ICR was also first discovered in transgenic Drosophila, where noncoding RNA production from the transgenic insert was associated with reporter gene silencing [162]. The upstream H19 ICR is necessary for proper repression of paternal H19 expression in mice [163], where the noncoding transcripts are thought to be involved in the recruitment of other silencing mechanisms [162]. Both of these studies involving the transgenic mouse H19 ICR identified endogenous silencing mechanisms using a transgenic system, demonstrating the potential for epigenetic regulatory fidelity between two distinct organisms.

The Drosophila insulator $\mathrm{Su}(\mathrm{Hw})$ and Polycomb group proteins, Enhancer of zeste $(\mathrm{E}(\mathrm{z}))$ and Posterior sex combs (Psc), were found to regulate the transgenic Igf2/H19 ICR construct [164]. These results show that imprinted transgenes are able to recruit histone modifiers and chromatin remodelers to direct silencing of a chromosomal domain. The binding of $\mathrm{Su}(\mathrm{Hw})$ to the transgenic Igf2/H19 ICR construct is reminiscent of CTCF binding to the endogenous H19 ICR in mice [68]. In mice, CTCF protects H19 from methylation and silencing, whereas in Drosophila $\mathrm{Su}(\mathrm{Hw})$, binding to the H19 ICR initiates downstream silencing, possibly by the recruitment of heterochromatic factors. The involvement of $\mathrm{Su}(\mathrm{Hw})$ with silencing from the $\mathrm{H} 19$ ICR is specific to this imprinted element. Typically, $\mathrm{Su}(\mathrm{Hw})$ protects transgenes from silencing in Drosophila [165] and other ICRs are not dependent on $\mathrm{Su}(\mathrm{Hw})$ for silencing in transgenic Drosophila [164]. This unexpected involvement of $\mathrm{Su}(\mathrm{Hw})$ with the H19 ICR suggests that elements within the ICR are eliciting a genomic response from Drosophila that are beyond that of a nondescript repetitive element.

An intriguing finding from the mammal-Drosophila transgenic imprinting experiments is that silencing activity is often maintained, but the insulator/boundary activity necessary for maintaining gene expression is lost. Expression from an imprinted domain requires the parent-specific recruitment of both silencing and activating chromatin remodelers, which includes insulators. Binding of $\mathrm{Su}(\mathrm{Hw})$ to the transgenic H19 ICR did not produce the same insulator properties as endogenous CTCF binding provides, but, rather, acted as a silencer [164]. Furthermore, multiple transgenic constructs, produced from sections of both human and mouse H19 ICRs, all acted as silencing elements in Drosophila but did not retain any of their insulator functions [166]. These findings could suggest that the maintenance of the active component of imprinted regions might be equally as complex as the silenced component and may require species-specific recognition of epigenetic marks. The complexity of imprinted large domains and their association with repressed repetitive elements could favor robust regulatory mechanisms to ensure the maintenance of active imprinted alleles, as exemplified by the 
complex intrachromosomal folding associated with maternal activation of H19 (Figure 1(b)). Together, these transgenic experiments show that while many epigenetic mechanisms utilized for silencing genes are highly conserved, the elements that superimpose the parental specificity of silencing are more specialized and tailored to the regulatory needs of each species.

\section{Common Epigenetic Mechanisms Regulate Diverse Imprinted Domains}

Producing parent-specific expression requires independent regulation of the maternal and paternal alleles. Histone modification and DNA methylation, leading to heterochromatin formation, are common regulators of imprinted silencing. Noncoding RNA and RNAi are emerging as critical components for the early recruitment of silencing mechanisms to ICRs. Boundary elements have also been shown to be necessary to maintain discrete regulatory domains by protecting active alleles, in a parent-specific manner, from silencing by blocking either the recruitment or spreading of silencing mechanisms. In all cases, genomic imprinting relies on multiple epigenetic mechanisms acting in concert to maintain and reinforce silencing.

The recent identification of $\mathrm{H} 3 \mathrm{~K} 4, \mathrm{H} 3 \mathrm{~K} 9$, and $\mathrm{H} 4 \mathrm{~K} 20$ trimethylation as an epigenetic marks common to imprinted genes in mice is a significant step in understanding the epigenetic code that constitutes the demarcation of a genomic imprint [83]. As high-throughput screening of genome-wide epigenetic modifications is explored in more organisms, it will be interesting to see if a similar, concise pattern of epigenetic modifications emerges. In Drosophila, both $\mathrm{H} 3 \mathrm{~K} 9$ and $\mathrm{H} 3 \mathrm{~K} 4$ methylation are associated with the $D p(1 ; f) L J 9$ imprinted domain, while H3K27 methylation is not [128]. The finding that H3K27 trimethylation was found at some, but not all, imprinted genes in mice [83], yet is the primary histone modification associated with imprinting in Arabidopsis, may reflect the role of $\mathrm{H} 3 \mathrm{~K} 27$ trimethylation as a ubiquitous epigenetic modification in Arabidopsis [167]. This highlights that species-specific variations in the use of epigenetic regulators such as DNA methylation or RNAi will be reflected in how an imprinted region is regulated. Variation in the structure of an imprinted domain, and the organism in which it found, will result in differential reliance on specific epigenetic mechanisms and, possibly, the order in which they are recruited. Evolutionary pressures and the species-specific arrangement of chromosomes also factor into the construction of large imprinted domains or novel genes acquiring imprinted regulation. Nevertheless, in all species examined here, common suites of epigenetic processes appear to be employed to regulate genomic imprinting.

The study of genomic imprinting has progressed for the better part of a century but it is still very much in its infancy. Complex regulatory patterns continue to be revealed within known imprinted regions and new imprinted genes continue to be discovered. Assessing imprinting in diverse model and nonmodel organisms can broaden the understanding of what epigenetic processes are necessary to achieve an imprint. Despite the fact that specific imprinted genes are not often conserved between diverse species, the epigenetic mechanisms and gross structural features of imprinted regions are often similar. Recognizing the common processes of genomic imprinting will aid our understanding of the epigenetic mechanisms required to distinguish maternal and paternal genomes during development in both model and nonmodel organisms.

\section{Acknowledgments}

The author would like to thank V. K. Lloyd (Mount Allison University, Canada) for sharing unpublished observations. He would like to acknowledge V. K. Lloyd and D. V. Clark for critical review and discussion of the manuscript. This work was supported through funding from the Natural Sciences and Engineering Research Council of Canada, the Nova Scotia Health Research Foundation, and the Dalhousie University Patrick Lett fund.

\section{References}

[1] W. Reik and J. Walter, "Genomic imprinting: parental influence on the genome," Nature Reviews Genetics, vol. 2, no. 1, pp. 21-32, 2001.

[2] I. M. Morison, J. P. Ramsay, and H. G. Spencer, "A census of mammalian imprinting," Trends in Genetics, vol. 21, no. 8, pp. 457-465, 2005.

[3] M. B. Renfree, T. A. Hore, G. Shaw, J. A. Marshall Graves, and A. J. Pask, "Evolution of genomic imprinting: insights from marsupials and monotremes," Annual Review of Genomics and Human Genetics, vol. 10, pp. 241-262, 2009.

[4] C. M. Brideau, K. E. Eilertson, J. A. Hagarman, C. D. Bustamante, and P. D. Soloway, "Successful computational prediction of novel imprinted genes from epigenomic features," Molecular and Cellular Biology, vol. 30, no. 13, pp. 3357-3370, 2010.

[5] B. Tycko and I. M. Morison, "Physiological functions of imprinted genes," Journal of Cellular Physiology, vol. 192, no. 3, pp. 245-258, 2002.

[6] K. Delaval and R. Feil, "Epigenetic regulation of mammalian genomic imprinting," Current Opinion in Genetics and Development, vol. 14, no. 2, pp. 188-195, 2004.

[7] H. Royo and J. Cavaillé, "Non-coding RNAs in imprinted gene clusters," Biology of the Cell, vol. 100, no. 3, pp. 149-166, 2008.

[8] D. Monk, P. Arnaud, S. Apostolidou et al., "Limited evolutionary conservation of imprinting in the human placenta," Proceedings of the National Academy of Sciences of the United States of America, vol. 103, no. 17, pp. 6623-6628, 2006.

[9] O. Garnier, S. Laoueillé-Duprat, and C. Spillane, "Genomic imprinting in plants," Epigenetics, vol. 3, no. 1, pp. 14-20, 2008.

[10] M. T. Raissig, C. Baroux, and U. Grossniklaus, "Regulation and flexibility of genomic imprinting during seed development," Plant Cell, vol. 23, no. 1, pp. 16-26, 2011.

[11] V. Lloyd, "Parental imprinting in Drosophila," Genetica, vol. 109, no. 1-2, pp. 35-44, 2000.

[12] R. A. McGowan and C. C. Martin, "DNA methylation and genome imprinting in the zebrafish, Danio rerio: some 
evolutionary ramifications," Current Opinion in Genetics \& Development, vol. 75, no. 5, pp. 499-506, 1997.

[13] C. J. Bean, C. E. Schaner, and W. G. Kelly, "Meiotic pairing and imprinted $\mathrm{X}$ chromatin assembly in Caenorhabditis elegans," Nature Genetics, vol. 36, no. 1, pp. 100-105, 2004.

[14] K. Sha and A. Fire, "Imprinting capacity of gamete lineages in Caenorhabditis elegans," Genetics, vol. 170, no. 4, pp. 1633 1652, 2005.

[15] S. Suzuki, R. Ono, T. Narita et al., "Retrotransposon silencing by DNA methylation can drive mammalian genomic imprinting," PLoS Genetics, vol. 3, no. 4, p. e55, 2007.

[16] A. J. Pask, A. T. Papenfuss, E. I. Ager, K. A. McColl, T. P. Speed, and M. B. Renfree, "Analysis of the platypus genome suggests a transposon origin for mammalian imprinting," Genome Biology, vol. 10, no. 1, p. R1, 2009.

[17] F. Pardo-Manuel de Villena, E. De la Casa-Esperón, and C. Sapienza, "Natural selection and the function of genome imprinting: beyond the silenced minority," Trends in Genetics, vol. 16, no. 12, pp. 573-579, 2000.

[18] C. Sapienza, A. C. Peterson, J. Rossant, and R. Balling, "Degree of methylation of transgenes is dependent on gamete of origin,” Nature, vol. 328, no. 6127, pp. 251-254, 1987.

[19] W. Reik, A. Collick, and M. L. Norris, "Genomic imprinting determines methylation of parental alleles in transgenic mice," Nature, vol. 328, no. 6127, pp. 248-251, 1987.

[20] F. Spada, A. Haemmer, D. Kuch et al., "DNMT1 but not its interaction with the replication machinery is required for maintenance of DNA methylation in human cells," Journal of Cell Biology, vol. 176, no. 5, pp. 565-571, 2007.

[21] W. Xiao, R. D. Custard, R. C. Brown et al., "DNA methylation is critical for Arabidopsis embroyogenesis and seed viability," Plant Cell, vol. 18, no. 4, pp. 805-814, 2006.

[22] F. Lyko, B. H. Ramsahoye, and R. Jaenisch, "DNA methylation in Drosophila melanogaster," Nature, vol. 408, no. 6812, pp. 538-540, 2000.

[23] S. L. Berger, "Histone modifications in transcriptional regulation," Current Opinion in Genetics and Development, vol. 12, no. 2, pp. 142-148, 2002.

[24] P. Cheung and P. Lau, "Epigenetic regulation by histone methylation and histone variants," Molecular Endocrinology, vol. 19, no. 3, pp. 563-573, 2005.

[25] M. Tariq and J. Paszkowski, "DNA and histone methylation in plants," Trends in Genetics, vol. 20, no. 6, pp. 244-251, 2004.

[26] H. Cedar and Y. Bergman, "Linking DNA methylation and histone modification: patterns and paradigms," Nature Reviews Genetics, vol. 10, no. 5, pp. 295-304, 2009.

[27] R. T. Kamakaka, "Heterochromatin: proteins in flux lead to stable repression," Current Biology, vol. 13, no. 8, pp. R317R319, 2003.

[28] J. C. Eissenberg and S. C. Elgin, "The HP1 protein family: getting a grip on chromatin," Current Opinion in Genetics and Development, vol. 10, no. 2, pp. 204-210, 2000.

[29] S. I. S. Grewal and S. C. R. Elgin, "Heterochromatin: new possibilities for the inheritance of structure," Current Opinion in Genetics and Development, vol. 12, no. 2, pp. 178$187,2002$.

[30] T. C. James and S. C. Elgin, "Identification of a nonhistone chromosomal protein associated with heterochromatin in Drosophila melanogaster and its gene," Molecular and Cellular Biology, vol. 6, no. 11, pp. 3862-3872, 1986.

[31] V. Orlando, "Polycomb, epigenomes, and control of cell identity," Cell, vol. 112, no. 5, pp. 599-606, 2003.
[32] W. Filipowicz, "RNAi: the nuts and bolts of the RISC machine," Cell, vol. 122, no. 1, pp. 17-20, 2005.

[33] G. Tang, "siRNA and miRNA: an insight into RISCs," Trends in Biochemical Sciences, vol. 30, no. 2, pp. 106-114, 2005.

[34] Y. Zhang and L. Qu, "Non-coding RNAs and the acquisition of genomic imprinting in mammals," Science in China C, vol. 52, no. 3, pp. 195-204, 2009.

[35] I. Djupedal and K. Ekwall, "Epigenetics: heterochromatin meets RNAi," Cell Research, vol. 19, no. 3, pp. 282-295, 2009.

[36] B. Hutter, V. Helms, and M. Paulsen, "Tandem repeats in the CpG islands of imprinted genes," Genomics, vol. 88, no. 3, pp. 323-332, 2006.

[37] T. Babak, B. DeVeale, C. Armour et al., "Global survey of genomic imprinting by transcriptome sequencing," Current Biology, vol. 18, no. 22, pp. 1735-1741, 2008.

[38] M. S. Bartolomei, S. Zemel, and S. M. Tilghman, "Parental imprinting of the mouse $H 19$ gene," Nature, vol. 351, no. 6322, pp. 153-155, 1991.

[39] T. M. DeChiara, E. J. Robertson, and A. Efstratiadis, "Parental imprinting of the mouse insulin-like growth factor II gene," Cell, vol. 64, no. 4, pp. 849-859, 1991.

[40] N. Giannoukakis, C. Deal, J. Paquette, C. G. Goodyer, and C. Polychronakos, "Parental genomic imprinting of the human IGF2 gene," Nature Genetics, vol. 4, no. 1, pp. 98-101, 1993.

[41] Y. Zhang and B. Tycko, "Monoallelic expression of the human H19 gene," Nature Genetics, vol. 1, no. 1, pp. 40-44, 1992.

[42] S. V. Dindot, K. C. Kent, B. Evers, N. Loskutoff, J. Womack, and J. A. Piedrahita, "Conservation of genomic imprinting at the XIST, IGF2, and GTL2 loci in the bovine," Mammalian Genome, vol. 15, no. 12, pp. 966-974, 2004.

[43] B. R. Lawton, L. Sevigny, C. Obergfell, D. Reznick, R. J. O'Neill, and M. J. O'Neill, "Allelic expression of IGF2 in live-bearing, matrotrophic fishes," Development Genes and Evolution, vol. 215, no. 4, pp. 207-212, 2005.

[44] C. M. Nolan, J. Keith Killian, J. N. Petitte, and R. L. Jirtle, "Imprint status of M6P/IGF2R and IGF2 in chickens," Development Genes and Evolution, vol. 211, no. 4, pp. 179183, 2001.

[45] S. Suzuki, M. B. Renfree, A. J. Pask et al., "Genomic imprinting of IGF2, p57KIP2 and PEG1/MEST in a marsupial, the tammar wallaby," Mechanisms of Development, vol. 122, no. 2, pp. 213-222, 2005.

[46] A. Thurston, J. Taylor, J. Gardner, K. D. Sinclair, and L. E. Young, "Monoallelic expression of nine imprinted genes in the sheep embryo occurs after the blastocyst stage," Reproduction, vol. 135, no. 1, pp. 29-40, 2008.

[47] M. Constância, W. Dean, S. Lopes, T. Moore, G. Kelsey, and W. Reik, "Deletion of a silencer element in Igf2 results in loss of imprinting independent of H19," Nature Genetics, vol. 26, no. 2, pp. 203-206, 2000.

[48] A. Murrell, S. Heeson, L. Bowden et al., "An intragenic methylated region in the imprinted Igf2 gene augments transcription," EMBO Reports, vol. 2, no. 12, pp. 1101-1106, 2001.

[49] M. S. Bartolomei, A. L. Webber, M. E. Brunkow, and S. M. Tilghman, "Epigenetic mechanisms underlying the imprinting of the mouse H19 gene," Genes and Development, vol. 7, no. 9, pp. 1663-1673, 1993.

[50] K. L. Arney, "H19 and Igf2- Enhancing the confusion?" Trends in Genetics, vol. 19, no. 1, pp. 17-23, 2003.

[51] K. L. Tucker, C. Beard, J. Dausman et al., "Germ-line passage is required for establishment of methylation and expression patterns of imprinted but not of nonimprinted genes," Genes and Development, vol. 10, no. 8, pp. 1008-1020, 1996. 
[52] I. Suetake, F. Shinozaki, J. Miyagawa, H. Takeshima, and S. Tajima, "DNMT3L stimulates the DNA methylation activity of Dnmt3a and Dnmt3b through a direct interaction," Journal of Biological Chemistry, vol. 279, no. 26, pp. 2781627823, 2004.

[53] M. Kaneda, M. Okano, K. Hata et al., "Essential role for de novo DNA methyltransferase Dnmt3a in paternal and maternal imprinting," Nature, vol. 429, no. 6994, pp. 900903, 2004.

[54] R. Hirasawa, H. Chiba, M. Kaneda et al., "Maternal and zygotic Dnmtl are necessary and sufficient for the maintenance of DNA methylation imprints during preimplantation development," Genes and Development, vol. 22, no. 12, pp. 1607-1616, 2008.

[55] W. Reik, W. Dean, and J. Walter, "Epigenetic reprogramming in mammalian development," Science, vol. 293, no. 5532, pp. 1089-1093, 2001.

[56] N. Lane, W. Dean, S. Erhardt et al., "Resistance of IAPs to methylation reprogramming may provide a mechanism for epigenetic inheritance in the mouse," Genesis, vol. 35, no. 2, pp. 88-93, 2003.

[57] M. S. Bartolomei, "Genomic imprinting: employing and avoiding epigenetic processes," Genes and Development, vol. 23, no. 18, pp. 2124-2133, 2009.

[58] N. Beaujean, G. Hartshorne, J. Cavilla et al., "Nonconservation of mammalian preimplantation methylation dynamics," Current Biology, vol. 14, no. 7, pp. R266-R267, 2004.

[59] J. Hou, L. Liu, J. Zhang et al., "Epigenetic modification of histone 3 at lysine 9 in sheep zygotes and its relationship with DNA methylation," BMC Developmental Biology, vol. 8, no. 1, article 60, 2008.

[60] A. Colosimo, G. Di Rocco, V. Curini et al., "Characterization of the methylation status of five imprinted genes in sheep gametes," Animal Genetics, vol. 40, no. 6, pp. 900-908, 2009.

[61] K. Y. Park, E. A. Sellars, A. Grinberg, S. P. Huang, and K. Pfeifer, "The $H 19$ differentially methylated region marks the parental origin of a heterologous locus without gametic DNA methylation," Molecular and Cellular Biology, vol. 24, no. 9, pp. 3588-3595, 2004.

[62] C. Gebert, D. Kunkel, A. Grinberg, and K. Pfeifer, "H19 imprinting control region methylation requires an imprinted environment only in the male germ line," Molecular and Cellular Biology, vol. 30, no. 5, pp. 1108-1115, 2010.

[63] M. R. W. Mann, S. S. Lee, A. S. Doherty et al., "Selective loss of imprinting in the placenta following preimplantation development in culture," Development, vol. 131, no. 15, pp. 3727-3735, 2004.

[64] B. A. Market-Velker, L. Zhang, L. S. Magri, A. C. Bonvissuto, and M. R. W. Mann, "Dual effects of superovulation: loss of maternal and paternal imprinted methylation in a dosedependent manner," Human Molecular Genetics, vol. 19, no. 1, Article ID ddp465, pp. 36-51, 2010.

[65] A. Murrell, S. Heeson, and W. Reik, "Interaction between differentially methylated regions partitions the imprinted genes Igf2 and H19 into parent-specific chromatin loops," Nature Genetics, vol. 36, no. 8, pp. 889-893, 2004.

[66] J. Gribnau, K. Hochedlinger, K. Hata, E. Li, and R. Jaenisch, "Asynchronous replication timing of imprinted loci is independent of DNA methylation, but consistent with differential subnuclear localization," Genes and Development, vol. 17, no. 6, pp. 759-773, 2003.

[67] F. Cerrato, W. Dean, K. Davies et al., "Paternal imprints can be established on the maternal Igf2-H19 locus without altering replication timing of DNA," Human Molecular Genetics, vol. 12, no. 23, pp. 3123-3132, 2003.

[68] P. E. Szabó, S. H. E. Tang, F. J. Silva, W. M. K. Tsark, and J. R. Mann, "Role of CTCF binding sites in the Igf2/H19 imprinting control region," Molecular and Cellular Biology, vol. 24, no. 11, pp. 4791-4800, 2004.

[69] A. C. Bell and G. Felsenfeld, "Methylation of a CTCFdependent boundary controls imprinted expression of the Igf2 gene," Nature, vol. 405, no. 6785, pp. 482-485, 2000.

[70] A. T. Hark, C. J. Schoenherr, D. J. Katz, R. S. Ingram, J. M. Levorse, and S. M. Tilghman, "CTCF mediates methylationsensitive enhancer-blocking activity at the H19/Igf2 locus," Nature, vol. 405, no. 6785, pp. 486-489, 2000.

[71] S. Lopes, A. Lewis, P. Hajkova et al., "Epigenetic modifications in an imprinting cluster are controlled by a hierarchy of DMRs suggesting long-range chromatin interactions," Human Molecular Genetics, vol. 12, no. 3, pp. 295-305, 2003.

[72] A. M. Fedoriw, P. Stein, P. Svoboda, R. M. Schultz, and M. S. Bartolomei, "Transgenic RNAi Reveals Essential Function for CTCF in $H 19$ Gene Imprinting," Science, vol. 303, no. 5655, pp. 238-240, 2004.

[73] J. R. Weidman, S. K. Murphy, C. M. Nolan, F. S. Dietrich, and R. L. Jirtle, "Phylogenetic footprint analysis of IGF2 in extant mammals," Genome Research, vol. 14, no. 9, pp. 1726-1732, 2004.

[74] G. N. Filippova, "Genetics and epigenetics of the multifunctional protein CTCF," Current Topics in Developmental Biology, vol. 80, pp. 337-360, 2008.

[75] T. Li, J. F. Hu, X. Qiu et al., "CTCF regulates allelic expression of Igf2 by orchestrating a promoter-polycomb repressive complex 2 intrachromosomal loop," Molecular and Cellular Biology, vol. 28, no. 20, pp. 6473-6482, 2008.

[76] S. Kurukuti, V. K. Tiwari, G. Tavoosidana et al., "CTCF binding at the H19 imprinting control region mediates maternally inherited higher-order chromatin conformation to restrict enhancer access to Igf2," Proceedings of the National Academy of Sciences of the United States of America, vol. 103, no. 28, pp. 10684-10689, 2006.

[77] L. B. Wan and M. S. Bartolomei, "Regulation of imprinting in clusters: noncoding RNAs versus insulators," Advances in Genetics, vol. 61, pp. 207-223, 2008.

[78] D. P. Barlow, R. Stoger, B. G. Herrmann, K. Saito, and N. Schweifer, "The mouse insulin-like growth factor type-2 receptor is imprinted and closely linked to the Tme locus," Nature, vol. 349, no. 6304, pp. 84-87, 1991.

[79] J. F. Wilkins and D. Haig, "What good is genomic imprinting: the function of parent-specific gene expression," Nature Reviews Genetics, vol. 4, no. 5, pp. 359-368, 2003.

[80] F. Sleutels, R. Zwart, and D. P. Barlow, "The non-coding Air RNA is required for silencing autosomal imprinted genes," Nature, vol. 415, no. 6873, pp. 810-813, 2002.

[81] T. H. Vu, T. Li, and A. R. Hoffman, "Promoter-restricted histone code, not the differentially methylated DNA regions or antisense transcripts, marks the imprinting status of $I G F 2 R$ in human and mouse," Human Molecular Genetics, vol. 13, no. 19, pp. 2233-2245, 2004.

[82] D. N. Ciccone, H. Su, S. Hevi et al., "KDM1B is a histone H3K4 demethylase required to establish maternal genomic imprints," Nature, vol. 461, no. 7262, pp. 415-418, 2009.

[83] K. R. McEwen and A. C. Ferguson-Smith, "Distinguishing epigenetic marks of developmental and imprinting regulation," Epigenetics and Chromatin, vol. 3, no. 1, article 2, 2010.

[84] P. Singh, X. Wu, D. -H. Lee et al., "Chromosome-wide analysis of parental allele-specific chromatin and DNA 
methylation," Molecular and Cellular Biology, vol. 31, no. 8, pp. 1757-1770, 2011.

[85] A. M. Lindroth, J. P. Yoon, C. M. McLean et al., "Antagonism between DNA and H3K27 methylation at the imprinted Rasgrf1 locus," PLoS Genetics, vol. 4, no. 8, Article ID e1000145, 2008.

[86] A. Wutz, O. W. Smrzka, N. Schweifer, K. Schellander, E. F. Wagner, and D. P. Barlow, "Imprinted expression of the Igf $2 r$ gene depends on an intronic CpG island," Nature, vol. 389, no. 6652, pp. 745-749, 1997.

[87] F. Sleutels, G. Tjon, T. Ludwig, and D. P. Barlow, "Imprinted silencing of Slc22a2 and Slc22a3 does not need transcriptional overlap between Igf2r and Air," EMBO Journal, vol. 22, no. 14, pp. 3696-3704, 2003.

[88] T. Nagano, J. A. Mitchell, L. A. Sanz et al., "The Air noncoding RNA epigenetically silences transcription by targeting G9a to chromatin," Science, vol. 322, no. 5908, pp. 17171720, 2008.

[89] C. I. M. Seidl, S. H. Stricker, and D. P. Barlow, “The imprinted Air ncRNA is an atypical RNAPII transcript that evades splicing and escapes nuclear export," EMBO Journal, vol. 25, no. 15, pp. 3565-3575, 2006.

[90] S. H. Stricker, L. Steenpass, F. M. Pauler et al., "Silencing and transcriptional properties of the imprinted Airn ncRNA are independent of the endogenous promoter," EMBO Journal, vol. 27, no. 23, pp. 3116-3128, 2008.

[91] M. C. Golding, L. S. Magri, L. Zhang, S. A. Lalone, M. J. Higgins, and M. R.W. Mann, "Depletion of kcnq1ot1 noncoding rna does not affect imprinting maintenance in stem cells," Development, vol. 138, no. 17, pp. 3667-3678, 2011.

[92] Y. Zeng, R. Yi, and B. R. Cullen, "MicroRNAs and small interfering RNAs can inhibit mRNA expression by similar mechanisms," Proceedings of the National Academy of Sciences of the United States of America, vol. 100, no. 17, pp. 97799784, 2003.

[93] C. Charlier, K. Segers, D. Wagenaar et al., "Human-ovine comparative sequencing of a $250-\mathrm{kb}$ imprinted domain encompassing the callipyge (clpg) locus and identification of six imprinted transcripts: DLK1, DAT, GTL2, PEG11, antiPEG11, and MEG8," Genome Research, vol. 11, no. 5, pp. 850-862, 2001.

[94] H. Seitz, N. Youngson, S. P. Lin et al., "Imprinted microRNA genes transcribed antisense to a reciprocally imprinted retrotransposon-like gene," Nature Genetics, vol. 34, no. 3, pp. 261-262, 2003.

[95] S. P. Lin, N. Youngson, S. Takada et al., "Asymmetric regulation of imprinting on the maternal and paternal chromosomes at the Dlk1-Gtl2 imprinted cluster on mouse chromosome 12," Nature Genetics, vol. 35, no. 1, pp. 97-102, 2003.

[96] K. Byrne, M. L. Colgrave, T. Vuocolo et al., "The imprinted retrotransposon-like gene PEG11 (RTL1) is expressed as a full-length protein in skeletal muscle from Callipyge sheep," PLoS ONE, vol. 5, no. 1, Article ID e8638, 2010.

[97] E. Davis, F. Caiment, X. Tordoir et al., "RNAi-mediated allelic trans-interaction at the imprinted Rtl1/Peg11 locus," Current Biology, vol. 15, no. 8, pp. 743-749, 2005.

[98] K. E. Latham, "X chromosome imprinting and inactivation in preimplantation mammalian embryos," Trends in Genetics, vol. 21, no. 2, pp. 120-127, 2005.

[99] A. A. Andersen and B. Panning, "Epigenetic gene regulation by noncoding RNAs," Current Opinion in Cell Biology, vol. 15, no. 3, pp. 281-289, 2003.
[100] S. Kalantry, S. Purushothaman, R. B. Bowen, J. Starmer, and T. Magnuson, "Evidence of Xist RNA-independent initiation of mouse imprinted X-chromosome inactivation," Nature, vol. 460, no. 7255, pp. 647-651, 2009.

[101] Y. Ogawa, B. K. Sun, and J. T. Lee, "Intersection of the RNA interference and X-inactivation pathways," Science, vol. 320, no. 5881, pp. 1336-1341, 2008.

[102] J. L. Kermicle, "Dependenct of the R-Mottled aleurone phenotype in maize on mode of sexual transmission," Genetics, vol. 66, no. 1, pp. 69-85, 1970.

[103] T. Kinoshita, A. Miura, Y. Choi et al., "One-way control of FWA imprinting in Arabidopsis endosperm by DNA methylation," Science, vol. 303, no. 5657, pp. 521-523, 2004.

[104] M. Gehring, J. H. Huh, T. F. Hsieh et al., "DEMETER DNA glycosylase establishes MEDEA polycomb gene selfimprinting by allele-specific demethylation," Cell, vol. 124, no. 3, pp. 495-506, 2006.

[105] Y. Choi, M. Gehring, L. Johnson et al., "DEMETER, a DNA glycosylase domain protein, is required for endosperm gene imprinting and seed viability in Arabidopsis," Cell, vol. 110, no. 1, pp. 33-42, 2002.

[106] P. E. Jullien, T. Kinoshita, N. Ohad, and F. Berger, "Maintenance of DNA methylation during the Arabidopsis life cycle is essential for parental imprinting," Plant Cell, vol. 18, no. 6, pp. 1360-1372, 2006.

[107] Z. Lippman and R. Martienssen, "The role of RNA interference in heterochromatic silencing," Nature, vol. 431, no. 7006, pp. 364-370, 2004.

[108] M. B. Wang, S. V. Wesley, E. J. Finnegan, N. A. Smith, and P. $\mathrm{M}$. Waterhouse, "Replicating satellite RNA induces sequencespecific DNA methylation and truncated transcripts in plants," RNA, vol. 7, no. 1, pp. 16-28, 2001.

[109] Z. Lippman, B. May, C. Yordan, T. Singer, and R. Martienssen, "Distinct mechanisms determine transposon inheritance and methylation via small interfering RNA and histone modification," PLoS Biology, vol. 1, no. 3, p. E67, 2003.

[110] S. W. L. Chan, D. Zilberman, Z. Xie, L. K. Johansen, J. C. Carrington, and S. E. Jacobsen, "RNA silencing genes control de novo DNA methylation," Science, vol. 303, no. 5662, p. 1336, 2004

[111] W. Xiao, M. Gehring, Y. Choi et al., "Imprinting of the MEA polycomb gene is controlled by antagonism between MET1 methyltransferase and DME glycosylase," Developmental Cell, vol. 5, no. 6, pp. 891-901, 2003.

[112] M. Luo, P. Bilodeau, E. S. Dennis, W. J. Peacock, and A. Chaudhury, "Expression and parent-of-origin effects for FIS2, MEA, and FIE in the endosperm and embryo of developing Arabidopsis seeds," Proceedings of the National Academy of Sciences of the United States of America, vol. 97, no. 19, pp. 10637-10642, 2000.

[113] P. E. Jullien, A. Katz, M. Oliva, N. Ohad, and F. Berger, "Polycomb group complexes self-regulate imprinting of the polycomb group gene MEDEA in Arabidopsis," Current Biology, vol. 16, no. 5, pp. 486-492, 2006.

[114] C. Köhler, D. R. Page, V. Gagliardini, and U. Grossniklaus, "The Arabidopsis thaliana MEDEA Polycomb group protein controls expression of PHERES1 by parental imprinting," Nature Genetics, vol. 37, no. 1, pp. 28-30, 2005.

[115] C. Köhler, L. Hennig, C. Spillane, S. Pien, W. Gruissem, and U. Grossniklaus, "The Polycomb-group protein MEDEA regulates seed development by controlling expression of the MADS-box gene PHERES1," Genes and Development, vol. 17, no. 12, pp. 1540-1553, 2003. 
[116] X. Wang, P. D. Soloway, and A. G. Clark, "A survey for novel imprinted genes in the mouse placenta by mRNA-seq," Genetics, vol. 189, no. 1, pp. 109-122, 2011.

[117] S. Jahnke and S. Scholten, "Epigenetic resetting of a gene imprinted in plant embryos," Current Biology, vol. 19, no. 19, pp. 1677-1681, 2009.

[118] C. W. Metz, "Chromosomes and sex in Sciara," Science, vol. 61, no. 1573, pp. 212-214, 1925.

[119] F. Schrader, "The chromosomes of Pseudococcus nipae," Biological Bulletin, vol. 40, no. 5, pp. 259-270, 1921.

[120] H. V. Crouse, "The controlling element in sex chromosome behavior in Sciara," Genetics, vol. 45, no. 10, pp. 1429-1443, 1960.

[121] B. B. Normark, "The evolution of alternative genetic systems in insects," Annual Review of Entomology, vol. 48, pp. 397423, 2003.

[122] M. Anaka, A. Lynn, P. McGinn, and V. K. Lloyd, "Genomic imprinting in Drosophila has properties of both mammalian and insect imprinting," Development Genes and Evolution, vol. 219, no. 2, pp. 59-66, 2009.

[123] K. A. Maggert and K. G. Golic, "The Y chromosome of Drosophila melanogaster exhibits chromosome-wide imprinting," Genetics, vol. 162, no. 3, pp. 1245-1258, 2002.

[124] B. S. Haller and R. C. Woodruff, "Varied expression of a Y-linked $\mathrm{P}[\mathrm{W}+]$ insert due to imprinting in Drosophila melanogaster," Genome, vol. 43, no. 2, pp. 285-292, 2000.

[125] J. Cohen, "Position-effect variegation at several closely linked loci in Drosophila melanogaster," Gerontologia Clinica, vol. 47, pp. 647-659, 1962.

[126] V. K. Lloyd, D. A. Sinclair, and T. A. Grigliatti, "Genomic imprinting and position-effect variegation in Drosophila melanogaster," Genetics, vol. 151, no. 4, pp. 1503-1516, 1999.

[127] R. W. Hardy, D. L. Lindsley, and K. J. Livak, "Cytogenetic analysis of a segment of the Y chromosome of Drosophila melanogaster," Genetics, vol. 107, no. 4, pp. 591-610, 1984.

[128] V. Joanis and V. Lloyd, "Genomic imprinting in Drosophila is maintained by the products of Suppressor of variegation and trithorax group, but not Polycomb group, genes," Molecular Genetics and Genomics, vol. 268, no. 1, pp. 103-112, 2002.

[129] T. Rudolph, M. Yonezawa, S. Lein et al., "Heterochromatin formation in Drosophila is initiated through active removal of H3K4 Methylation by the LSD1 Homolog SU(VAR)3-3," Molecular Cell, vol. 26, no. 1, pp. 103-115, 2007.

[130] S. Takeda and J. Paszkowski, "DNA methylation and epigenetic inheritance during plant gametogenesis," Chromosoma, vol. 115, no. 1, pp. 27-35, 2005.

[131] J. E. Phillips and V. G. Corces, "CTCF: master weaver of the genome," Cell, vol. 137, no. 7, pp. 1194-1211, 2009.

[132] T. A. Schoborg and M. Labrador, "The phylogenetic distribution of non-CTCF insulator proteins is limited to insects and reveals that beaf-32 is drosophila lineage specific," Journal of Molecular Evolution, vol. 70, no. 1, pp. 74-84, 2010.

[133] W. A. MacDonald, D. Menon, N. J. Bartlett et al., "The Drosophila homolog of the mammalian imprint regulator, CTCF, maintains the maternal genomic imprint in Drosophila melanogaster," BMC Biology, vol. 8, no. 1, article105, 2010.

[134] V. K. Lloyd, Unpublished Observations, Mount Allison University, Sackville NB, Canada, 2011.

[135] T. I. Gerasimova and V. G. Corces, "Polycomb and trithorax group proteins mediate the function of a chromatin insulator," Cell, vol. 92, no. 4, pp. 511-521, 1998.
[136] C. J. Schoenherr, J. M. Levorse, and S. M. Tilghman, "CTCF maintains differential methylation at the Igf2/H19 locus," Nature Genetics, vol. 33, no. 1, pp. 66-69, 2003.

[137] A. J. Haigh and V. K. Lloyd, "Loss of genomic imprinting in Drosophila clones," Genome, vol. 49, no. 8, pp. 1043-1046, 2006.

[138] J. M. Greally, T. A. Gray, J. M. Gabriel, L. Q. Song, S. Zemel, and R. D. Nicholls, "Conserved characteristics of heterochromatin-forming DNA at the 15q11-q13 imprinting center," Proceedings of the National Academy of Sciences of the United States of America, vol. 96, no. 25, pp. 14430-14435, 1999.

[139] X. Deng and V. H. Meller, "Non-coding RNA in fly dosage compensation," Trends in Biochemical Sciences, vol. 31, no. 9, pp. 526-532, 2006.

[140] X. Deng and V. H. Meller, "roX RNAs are required for increased expression of X-linked genes in Drosophila melanogaster males," Genetics, vol. 174, no. 4, pp. 1859-1866, 2006.

[141] R. L. Kelley, O. K. Lee, and Y. K. Shim, "Transcription rate of noncoding roX1 RNA controls local spreading of the Drosophila MSL chromatin remodeling complex," Mechanisms of Development, vol. 125, no. 11-12, pp. 1009-1019, 2008.

[142] D. U. Menon and V. H. Meller, "Imprinting of the Y chromosome influences dosage compensation in roX1 roX2 Drosophila melanogaster," Genetics, vol. 183, no. 3, pp. 811820, 2009.

[143] P. B. Vrana, J. A. Fossella, P. Matteson, T. Del Rio, M. J. O’Neill, and S. M. Tilghman, "Genetic and epigenetic incompatibilities underlie hybrid dysgenesis in peromyscus," Nature Genetics, vol. 25, no. 1, pp. 120-124, 2000.

[144] C. Josefsson, B. Dilkes, and L. Comai, "Parent-dependent loss of gene silencing during interspecies hybridization," Current Biology, vol. 16, no. 13, pp. 1322-1328, 2006.

[145] S. Bongiorni, O. Cintio, and G. Prantera, "The relationship between DNA methylation and chromosome imprinting in the Coccid Planococcus citri," Genetics, vol. 151, no. 4, pp. 1471-1478, 1999.

[146] S. Bongiorni, M. Pugnali, S. Volpi, D. Bizzaro, P. B. Singh, and G. Prantera, "Epigenetic marks for chromosome imprinting during spermatogenesis in Coccids," Chromosoma, vol. 118, no. 4, pp. 501-512, 2009.

[147] S. Bongiorni, B. Pasqualini, M. Taranta, P. B. Singh, and G. Prantera, "Epigenetic regulation of facultative heterochromatinisation in Planococcus citri via the $\mathrm{Me}(3) \mathrm{K} 9 \mathrm{H} 3-\mathrm{HP} 1$ $\mathrm{Me}$ (3)K20H4 pathway," Journal of Cell Science, vol. 120, no. 6, pp. 1072-1080, 2007.

[148] N. Kunert, J. Marhold, J. Stanke, D. Stach, and F. Lyko, "A Dnmt2-like protein mediates DNA methylation in Drosophila," Development, vol. 130, no. 21, pp. 5083-5090, 2003.

[149] M. Schaefer, J. P. Steringer, and F. Lyko, "The Drosophila cytosine-5 methyltransferase Dnmt2 is associated with the nuclear matrix and can access DNA during mitosis," PLoS ONE, vol. 3, no. 1, Article ID e1414, 2008.

[150] M. J. Lin, L. Y. Tang, M. N. Reddy, and C. K. J. Shen, "DNA methyltransferase gene dDnmt2 and longevity of Drosophila," Journal of Biological Chemistry, vol. 280, no. 2, pp. 861-864, 2005.

[151] S. Phalke, O. Nickel, D. Walluscheck, F. Hortig, M. C. Onorati, and G. Reuter, "Retrotransposon silencing and telomere integrity in somatic cells of Drosophila depends on 
the cytosine-5 methyltransferase DNMT2," Nature Genetics, vol. 41, no. 6, pp. 696-702, 2009.

[152] F. Lyko, B. H. Ramsahoye, H. Kashevsky et al., "Mammalian (cytosine-5) methyltransferases cause genomic DNA methylation and lethality in Drosophila," Nature Genetics, vol. 23, no. 3, pp. 363-366, 1999.

[153] A. Weyrich, X. Tang, G. Xu, A. Schrattenholz, C. Hunzinger, and W. Hennig, "Mammalian DNMTs in the male germ line DNA of Drosophila," Biochemistry and Cell Biology, vol. 86, no. 5, pp. 380-385, 2008.

[154] V. Krauss and G. Reuter, "DNA Methylation in drosophilaa critical evaluation," Progress in Molecular Biology and Translational Science, vol. 101, pp. 177-191, 2011.

[155] M. Schaefer and F. Lyko, "Lack of evidence for DNA methylation of Invader4 retroelements in Drosophila and implications for Dnmt2-mediated epigenetic regulation," Nature Genetics, vol. 42, no. 11, pp. 920-921, 2010.

[156] F. Lyko, J. D. Brenton, M. A. Surani, and R. Paro, "An imprinting element from the mouse $\mathrm{H} 19$ locus functions as a silencer in Drosophila," Nature Genetics, vol. 16, no. 2, pp. 171-173, 1997.

[157] F. Lyko, K. Buiting, B. Horsthemke, and R. Paro, "Identification of a silencing element in the human 15q11-q13 imprinting center by using transgenic Drosophila," Proceedings of the National Academy of Sciences of the United States of America, vol. 95, no. 4, pp. 1698-1702, 1998.

[158] S. Erhardt, F. Lyko, J. F. X. Ainscough, M. A. Surani, and R. Paro, "Polycomb-group proteins are involved in silencing processes caused by a transgenic element from the murine imprinted H19/Igf2 region in Drosophila," Development Genes and Evolution, vol. 213, no. 7, pp. 336-344, 2003.

[159] B. K. Jones, J. Levorse, and S. M. Tilghman, "A human H19 transgene exhibits impaired paternal-specific imprint acquisition and maintenance in mice," Human Molecular Genetics, vol. 11, no. 4, pp. 411-418, 2002.

[160] S. M. Blaydes, M. Elmore, T. Yang, and C. I. Brannan, "Analysis of murine Snrpn and human SBRPN gene imprinting in transgenic mice," Mammalian Genome, vol. 10, no. 6, pp. 549-555, 1999.

[161] J. D. Brenton, R. A. Drewell, S. Viville et al., "A silencer element identified in Drosophila is required for imprinting of H19 reporter transgenes in mice," Proceedings of the National Academy of Sciences of the United States of America, vol. 96, no. 16, pp. 9242-9247, 1999.

[162] S. Schoenfelder, G. Smits, P. Fraser, W. Reik, and R. Paro, "Non-coding transcripts in the H19 imprinting control region mediate gene silencing in transgenic Drosophila," EMBO Reports, vol. 8, no. 11, pp. 1068-1073, 2007.

[163] R. A. Drewell, J. D. Brenton, J. F. X. Ainscough et al., "Deletion of a silencer element disrupts H19 imprinting independently of a DNA methylation epigenetic switch," Development, vol. 127, no. 16, pp. 3419-3428, 2000.

[164] S. Schoenfelder and R. Paro, "Drosophila Su(Hw) regulates an evolutionarily conserved silencer from the mouse H19 imprinting control region," Cold Spring Harbor Symposia on Quantitative Biology, vol. 69, pp. 47-54, 2004.

[165] R. R. Roseman, V. Pirrotta, and P. K. Geyer, "The su(Hw) protein insulates expression of the Drosophila melanogaster white gene from chromosomal position-effects," EMBO Journal, vol. 12, no. 2, pp. 435-442, 1993.

[166] K. L. Arney, E. Bae, C. Olsen, and R. A. Drewell, "The human and mouse $\mathrm{H} 19$ imprinting control regions harbor an evolutionarily conserved silencer element that functions on transgenes in Drosophila," Development Genes and Evolution, vol. 216, no. 12, pp. 811-819, 2006.

[167] X. Zhang, O. Clarenz, S. Cokus et al., "Whole-genome analysis of histone $\mathrm{H} 3$ lysine 27 trimethylation in Arabidopsis," PLoS Biology, vol. 5, no. 5, p. e129, 2007. 

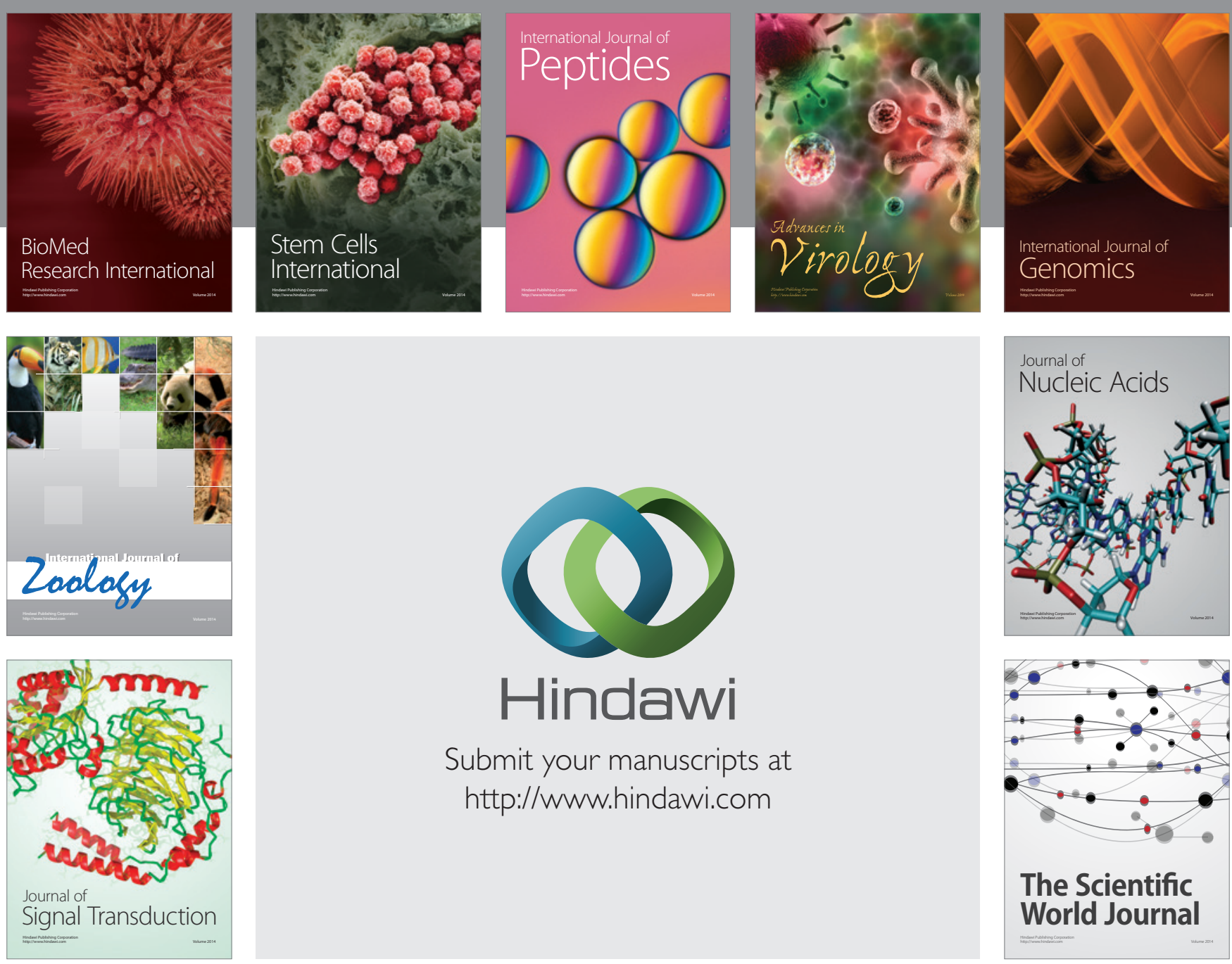

Submit your manuscripts at

http://www.hindawi.com
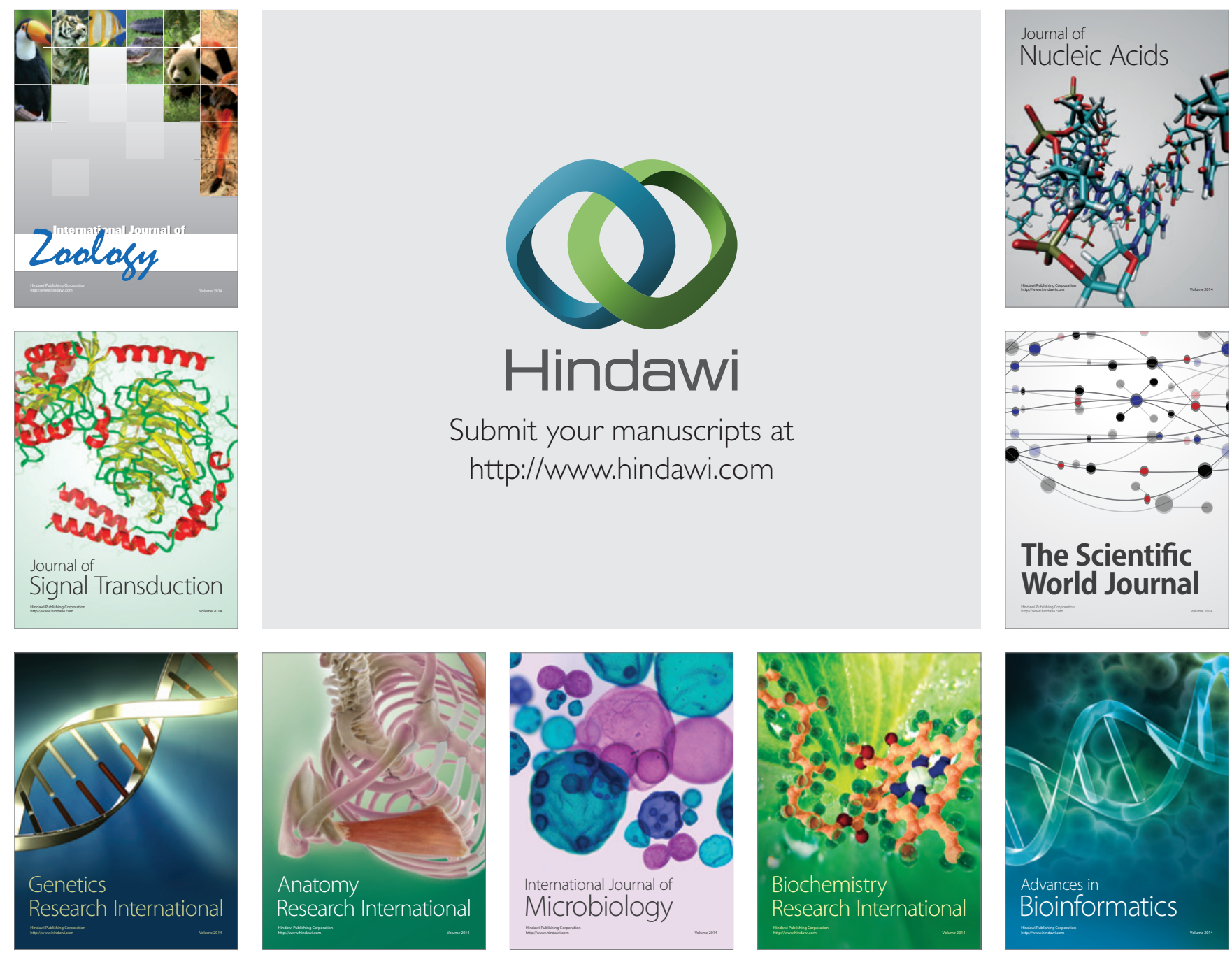

The Scientific World Journal
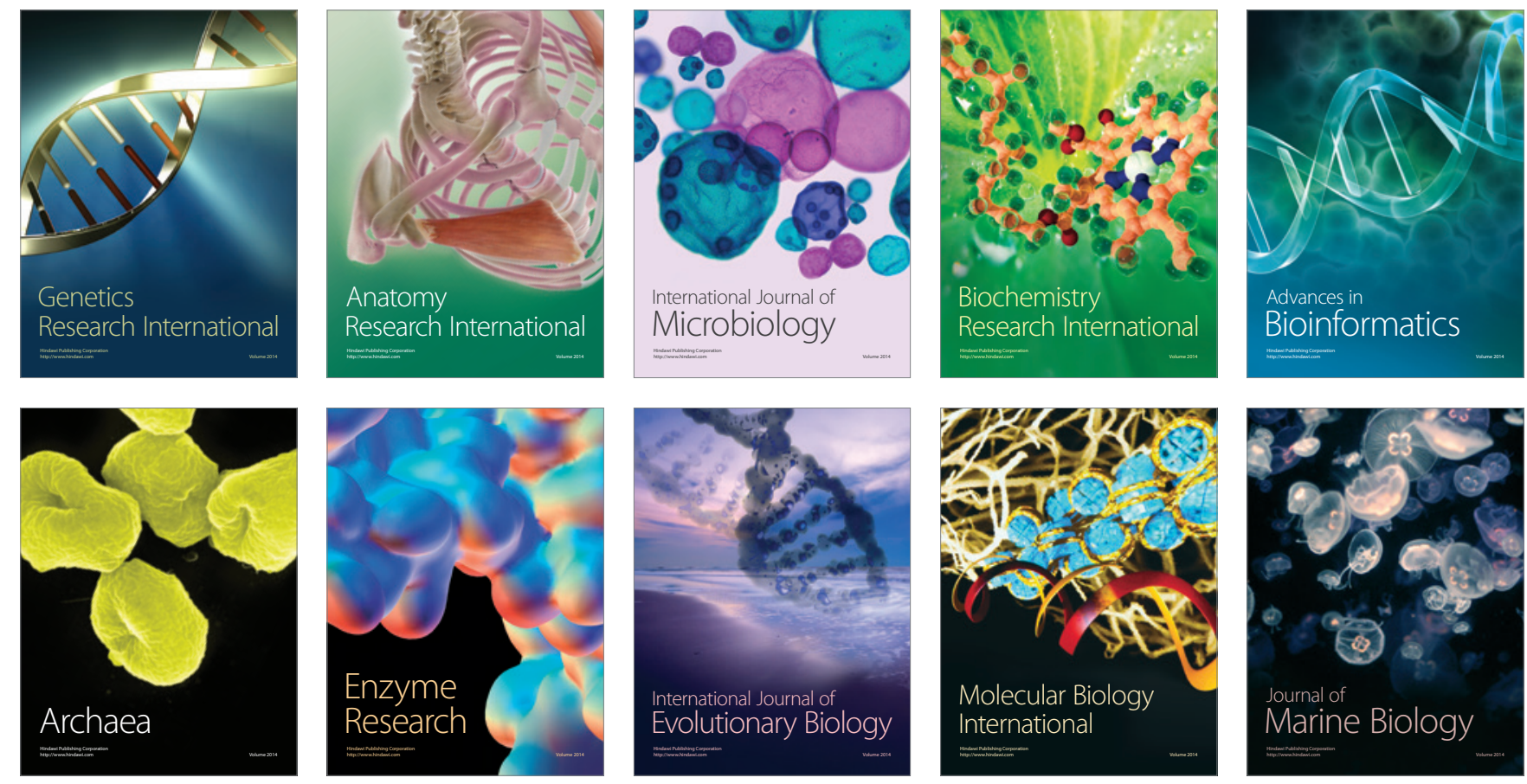